\title{
Towards a Comprehensive Understanding of Fertility: The Model of Dyadic Pathways
}

\author{
Uta Brehm, Norbert F. Schneider
}

\begin{abstract}
In this theoretical contribution, we propose a comprehensive and integrative heuristic model to explain fertility, the Model of Dyadic Pathways (MDP). We show how existing models such as the Theory of Planned Behaviour often do not withstand empirical challenges, especially not individual self-reports in qualitative studies. Furthermore, existing models vary in their premises and foci, resulting in a collection of models which do not necessarily align with or supplement one another. For these reasons, these heuristic models have been widely criticised and, in practice, pieced together according to the research question and tradition of the researcher. Against this backdrop, we establish the MDP to reconnect theory with reality and to unify a variety of approaches. The MDP is grounded on the dyad of partners as the prevalent basis of fertility. It integrates reasoned and unreasoned fertility behaviour, the impact of individual- and couple-level life course, soci(et) al conditions, and the body as an "actor". The model explicitly accounts for the variety of different real-life pathways that lead to fertility. It thereby encourages researchers to, first, consider all potentially relevant factors and their mechanisms and, second, think of fertility and its measurement as a multilinear process. Based on the presented elements a comprehensive model of fertility must cover, we suggest ways to improve surveys accordingly. Furthermore, we elaborate on the contributions and challenges the MDP presents to future fertility research.
\end{abstract}

Keywords: Fertility behaviour - Theory of planned behaviour - Decision-making heuristic $\cdot$ Dyadic relationship $\cdot$ Life-course analysis

\section{Introduction}

The challenge of understanding individual fertility behaviour and aggregated fertility trends has kept demographers, sociologists, and economists busy for decades. Recent years have brought about a new peak in fertility research, both empirically and theoretically. Empirically, researchers have set quantitative landmarks in the 
field, particularly research groups around Vienna's Wittgenstein Center and Milan's Bocconi University (e.g. Morgan et al. 2011; Balbo et al. 2013; Philipov et al. $2015 b)$. At the same time, theoretical approaches to fertility research have attracted increasing, and at times quite polarised, attention. This is especially true for the most prominent paradigm in the field, the Theory of Planned Behaviour (TPB, Ajzen 1991), which attributes fertility to reasoned intentions. The theory, or rather the heuristic model - as Liefbroer (2011) rightly argues to label it ${ }^{1}$ - has dominated the field for decades, influencing surveys such as the Generation and Gender Survey (GGS, Vikat et al. 2007) and acting as a go-to theoretical framework for many empirical studies. Beyond this dominance, there are other excellent heuristic models, such as the dyadic Traits-Desires-Intentions-Behaviour Model (TDIB, Miller/Pasta 1995) and the Cognitive-Social Model, also known as Theory of Conjunctural Action (TCA, Morgan/Bachrach 2011; Bachrach/Morgan 2013), which was developed to account for automatic cognition processes disregarded by the TPB. Beyond these tidily formulated models, there is of course a battery of ever-relevant utility-oriented approaches to explain and understand human fertility in terms of cost and benefit considerations (Becker 1960; Hoffman/Hoffman 1973). The result is a range of heuristic models ${ }^{2}$ with different premises, arguments, elements, and foci. Quantitative researchers draw upon these models and select them and their elements separately or complimentarily to frame their fertility research projects - depending on their data set, their specific research question, and their own or their topic's research tradition (see, for example, for the TPB: Billari et al. 2009; Kuhnt/Trappe 2013; Dommermuth et al. 2015; Philipov et al. 2015b; for the TDIB: Thomson/Hoem 1998; Rijken/Knijn 2009; Rosina/Testa 2009; Stein et al. 2014; for the TCA: Rackin/ Bachrach 2016; Shreffler et al. 2018; for utility-oriented approaches: Ekert-Jaffé et al. 2002; Klein/Eckhard 2007; Nauck 2007; Schippers 2011). Consequently, the field of quantitative fertility research is wide, diverse, and dispersed. Interestingly, qualitative fertility research is only affected by this intricacy to a lesser extent. Qualitative research has traditionally ventured beyond merely assessing problems against heuristic models. Thus, it has added relevant explanations and interrelationships to the understanding of fertility. These, however, have only rarely diffused into theoretical or quantitative approaches. Measured against elements which are taken to be essential to understanding fertility - such as the dyad of partners, reasoned and unreasoned behaviour, the life course, social and societal conditions, and the body - each of the prominent heuristic models has several blind spots.

In this article, we introduce the Model of Dyadic Pathways (MDP) as a decisionmaking heuristic and, as such, as a comprehensive foundation to fertility research.

1 Liefbroer (2011) evaluates the TPB with a set of characteristics, a theory must have, and concludes that the TPB is, instead, a heuristic model. We follow this approach and apply it to the other dominant fertility "theories".

2

There are, of course, more potentially relevant heuristic models which could be consulted to explain fertility. However, we limit our focus to these four dominant models, which have been well-received internationally, and have been adapted specifically to fertility research. 
First, the MDP aims to reconcile the frayed research strands of fertility studies by untangling the knots of existing models and neatly braiding them into one integrative model of fertility. The MDP thereby merges separate bodies of knowledge; it connects the dots and calls attention to unexplored areas. Second, we show that the MDP is firmly grounded in quantitative and, particularly, qualitative evidence: it pays due regard to the elements and perspectives that have been found to be relevant to fertility. Thereby, the MDP overcomes established yet rigid approaches of modelling fertility. Third, we illustrate that the MDP is a comprehensive as well as specific basis for all steps in fertility research: It provides links for several theories of decision-making and action, for different decisional pathways and logics, and thus for both testable hypotheses and counter-hypotheses. Due to this theoretical comprehensiveness, the MDP also offers a frame to survey development and methodological approaches.

We proceed as follows: first, we revisit the prevailing heuristic models, namely the Theory of Planned Behaviour, the Traits-Desires-Intentions-Behaviour Model, the Theory of Conjunctural Action, and utility-oriented approaches. We discuss the critiques of these models and extract concepts essential to understanding fertility: the dyad of partners, reasoned and unreasoned behaviour, the life course, social and societal conditions, and the body. In a second step, we reflect upon these essential concepts in light of empirical, mostly qualitative, fertility research, based on which we identify a variety of different pathways to fertility. In a third step, we assemble the established arguments and, step by step, integrate them into one comprehensive fertility model, the Model of Dyadic Pathways. Drawing upon this model, we illustrate, in a fourth step, how it integrates the pathway-variety by tracing example trails through the model. We make a point to use the emerging model not as a unilineal straitjacket, but rather to venture disaggregate it in order to cover the multitude of pathways that lead human beings to their resulting fertility. We conclude by assessing the Model of Dyadic Pathways' potential for fertility research as well as the challenges it poses to survey and analysis methodology.

\section{A critical discussion of heuristic models of fertility}

\subsection{Heuristic models of fertility - an overview}

\section{The Theory of Planned Behaviour (TPB)}

The dominant model in fertility research, the TPB, regards behaviour as a direct result of fertility intentions. Intentions, on the other hand, are contingent upon their antecedents, namely behavioural attitudes (i.e. beliefs about expected outcomes of a behaviour), social norms (i.e. beliefs about relatives' and peers' expectations and approval), and perceived behavioural control (i.e. beliefs about the capability and ability to pursue a behaviour). Perceived control is furthermore influenced by individuals' actual behavioural control, which also independently impacts the outcome. These three beliefs exert influence upon one another and are concurrently 
influenced by background factors such as socio-demographics, societal contexts, personal dispositions, and situational conditions (Ajzen 1991).

The TPB was developed as a social-psychological contribution to explaining behaviours and is not domain-specific to fertility research. Rather, it aims to offer a universal, individualistic, social-psychological model to understanding behaviour (Miller 2011; Philipov et al. 2015a). The TPB's wide application has, however, also lead to wide critical discussions of the framework. Though Ajzen has repeatedly and elaborately dismissed criticism (Ajzen 2011a, 2011b, 2014), some of the arguments die hard and will be taken up below.

The Traits-Desires-Intentions-Behaviour Model (TDIB)

A model which was explicitly developed to understand fertility behaviours is the TDIB (Miller/Pasta 1995, 1996; Miller et al. 2004). Similar to the TPB, it regards fertility behaviour as the result of intentions, and it in turn takes intentions to be the result of the desire to have children. It thus adds a relevant category which cannot be substituted by the TPB's behavioural attitudes (Miller 2011). Furthermore, by explicitly considering desires, the model allows for ambivalence, i.e. for individuals' simultaneous desires to have and not to have a child, as well as indifference in that regard (Miller/Pasta 2002; Barber et al. 2010; Miller 2011). The desires to have children are contingent upon motivational traits such as the feelings evoked by babies and childcare, which can be ambivalent. The motivational traits themselves are shaped by background factors similar to the ones considered in the TPB. Early on, the TDIB was adapted to all three manifestations of fertility behaviour: to have or not to have a child, when to have a child, and the number of children (Miller/Pasta 1994, 1995).

\section{The Theory of Conjunctural Action (TCA)}

Contrasting TPB's premise of reasoned actions, Morgan and Bachrach (2011) offered an alternative by explicitly modelling unreasoned behaviours and automatic, unconscious cognition in the Theory of Conjunctural Action (TCA), also known as the Cognitive-Social Model of Fertility (Morgan/Bachrach 2011; Johnson-Hanks et al. 2011; Bachrach/Morgan 2013). The TCA considers behaviour to be a result of the interplay of material or schematic structures on the one hand (i.e. observable behaviours or conditions and shared values, beliefs, norms, or conventions, respectively), and cognitive processes which happen automatically or are reasoned along these schemas, on the other. The material or schematic structures can impact behaviour in two ways: first, they constitute the situation in which people act, and second, they contribute to the formation of automatic cognitive schemas, together with individual schemas of semantic interpretation, of self-image, and of affect which develop across the life course. Reasoned cognition, in contrast, is only activated when necessary, e.g. in the face of inconsistencies or conflicts, because they are relatively costly and demanding. 
Utility-oriented approaches

Lastly, the literature offers many utility-oriented approaches to explain fertility. Comparable to the evolution of theories of decision-making and action theories, ${ }^{3}$ utility-oriented approaches have developed from the assumption of the actor as a strictly rational, utility maximising homo oeconomicus to actors with conditional, bounded rationality, personal preferences, and satisficing strategies.

Accordingly, economic cost-benefit analyses contrast the direct financial, temporal, and immaterial costs as well as opportunity costs with the financial, material, and immaterial benefits of having children (Becker 1960; Leibenstein 1974). These arguments have been transferred to the aforementioned manifestations of fertility behaviour: having children at all, timing them, and deciding on their number - though the former and the latter are often considered simultaneously. In this respect, Becker and Lewis (1973) hypothesised a trade-off between child quality in terms of investments in their education, health, and upbringing, and child quantity with regard to the number of children. Concerning their timing, considerations of the time to accumulate human capital and to seize its returns come into play, as well as the extent and speed of a possible human capital devaluation in the case of employment interruptions, and the respective opportunity costs (Becker 1991; Gustafsson 2001).

Advancing these notions, the Value of Children (VOC) approach considers children's benefit to parents in terms of economic utility (work and insurance utility), psychological satisfaction (stimulation, affection, and interaction), and social approval (social esteem, status attainment) (Hoffman/Hoffman 1973; Nauck 2014). In line with this argument, the anticipated number of children is, on the one hand, advanced by an increasing economic utility by child, followed by a subsequent saturation point of social approval and psychological satisfaction. On the other hand, it is confined by parents' opportunity structure and both economic and psychological costs. The development of VOC's implications for the timing of childbirth are, in large part, in the early stages (Nauck 2014), though Kağıtçıbaşı and Ataca (2005) discussed children's utility for social approval to accelerate childbirth among parents who face little economic or occupational prospects of social approval.

\subsection{Requirements for heuristic models of fertility}

The presented heuristic models of fertility behaviour have been widely applied in fertility research. With wide use comes great disapproval, however: The research community has identified a battery of additional requirements which a comprehensive model would have to meet. Following an in-depth literature review, we revisit the five aspects which we find to be essential. We summarise and systematise them and assess whether the previously presented heuristic models merit the criticism.

3 Consider, for example, the advancements of the homo oeconomicus by, e.g. Lindenberg (1985), Coleman (1990), Esser (1996), and Breen and Goldthorpe (1997). 
The dyad of partners

One line of criticism demands the integration of the dyad of partners, i.e. potential parents. The linked lives (Elder 1994) of partners influence one another in their thoughts and behaviours: they communicate needs and negotiate decisions, and, centrally, both contribute their fair share to the existence of a child. Some researchers thus argue that analysing the dyad is imperative to fertility research and requires explicit modelling (Miller/Pasta 1995, 1996; Miller 2011; Philipov 2011).

The TDIB accordingly implements that notion. Under the terms of the model, partners influence one another in their inner desires to have children and their intentions to act upon these desires prior to pursuing a joint fertility behaviour - directly as well as moderated by the perceived desires of the other person (Miller et al. 2004).

Similarly, the dyad of partners has attracted extensive attention in utility-oriented approaches: fertility decisions have been regarded as the result of bargaining construed from cooperative game theory. Bargaining models assume that each partner shapes the decision-making process to some degree, depending on threat points, interests, and resources. Accordingly, bargaining models address patriarchal and matriarchal rules, spheres of interest, power or joint utility rules, egalitarian or golden mean rules, veto player or social drift rules (Corijn et al. 1996; Jansen) Liefbroer 2006; Lundberg/Pollak 2007).

For the TPB, in contrast, Ajzen and Klobas (2013) stress that partners are already embedded in the existing model and therefore do not merit explicit mention - on the one hand, as important normative referents and, on the other hand, through indicators for an individual's behavioural control. Empirically, they treat the existence of partners as a prerequisite to fertility research. Similarly, the TCA also lacks an explicit integration of partners into its modelling of behaviour.

In sum, the dyad of partners, which is at the centre of fertility behaviour, is modelled explicitly only in the TDIB and in utility-oriented approaches. It is regarded only very marginally in the TPB and the TCA.

\section{Unreasoned behaviour}

Another pivotal criticism voiced by fertility researchers claims that not all fertility behaviour is preceded by clear reasoning and intentions, requiring fertility models to allow for unreasoned behaviour: Miller (2011; Miller/Pasta 2002) refers to "subintended" pregnancies that are neither intended nor unintended but rationalised posthoc. Barber (2011) calls "the heat of the moment" to attention, i.e. sexual arousal that leads to unintended conception. Morgan and Bachrach (2011; Bachrach/Morgan 2013) stress the importance of automatic cognition in situations that activate pre-existing mental schemas - and construct a new heuristic model around it. Thus, the primary addressees of the critique are approaches that solely assume rational or at least reasoned behaviour, particularly the TPB and utility-oriented approaches.

For the TPB, Ajzen (2011b) claims that emotions, irrationality, impulsivity, and automatic processing can be easily integrated into the model as background factors in the evolution of beliefs or indications of actual control. Nonetheless, critique 
remains that the model is thereby highly dependent on proxies, very much subject to researchers' interpretation, and thus relatively vague.

In the realm of utility-oriented approaches, in contrast, automatic cognition and unreasoned behaviour are barely considered. At their centre is rational thinking which directly opposes any behaviour that bypasses preceding intentions. This premise is one of the most crucial shortcomings of utility-oriented approaches when it comes to fertility behaviour.

Even in the TDIB, the process of translating desires into behaviour encompasses reasoned intentions - even though Miller and Pasta (2002) explicitly elaborate on unintended pregnancies. This might reflect imprecise phrasing in surveys (Philipov 2011) - Is "trying not to get pregnant" an indicator of intentions or of contraceptive behaviour? - But it might also reflect the conceptually undesignated direct, unconscious impact of, for example, desires on behaviour. Automatic cognition following pre-set schemas is only considered as a proxy in individuals' motivational traits (Miller et al. 2004).

Thus, the (in our view) substantiated critique of neglecting unreasoned fertility behaviour is directed at the TPB and utility-oriented approaches, but also at the TDIB. The TCA, in contrast, meets the requirement for automatic cognition and behaviour that bypasses reasoning.

\section{The life course}

Furthermore, there is a set of recurrently postulated requirements, model specifications, or extensions which, in our view, feature remarkable resemblances to Mayer's (2001) perspective on the life course.

A first argument is that fertility behaviour can be a side effect of other concurrent behaviours. Morgan and Bachrach (2011; Bachrach/Morgan 2013) and Barber (2011) stress that childbirth-invoking behaviours can be individually perceived as acts of relationship maintenance or continuation, as inattentiveness to contraception, or as anti-abortive behaviours. Adapting Mayer's (2001) Life Course Perspective, fertility behaviour is thus a multidimensional process: different areas of life - partnerships, sex, childbirth behaviour - develop alongside and in interdependence of one another.

A second recurring argument is that past as well as anticipated future behaviours crucially affect current fertility behaviours. Prominent examples are the impacts of the "age and stage" of individuals, the child parity at the time in question, individuals" experiences in previous and current relationships, and the balancing of births with a professional career (Ajzen/Klobas 2013; Spéder/Kapitány 2015). Similarly, fertility intentions have been argued to change, to potentially "zig-zag" across time (Morgan/ Bachrach 2011; Liefbroer 2011; Philipov 2011; Bachrach/Morgan 2013). In terms of Mayer's (2001) Life Course Perspective, this argumentation reflects the self-referentiality of the life course: The actions of a person are shaped and influenced by their accumulated experiences and resources (and not-cumulated resources such as the lack of contraceptive knowledge) as well as their future plans.

A third set of arguments refers to the relevance of societal contexts to fertility decisions (Liefbroer et al. 2015; Philipov et al. 2015b; Klobas/Ajzen 2015). In the light 
of Mayer's (2001) Life Course Perspective, this conceptualises the life course as a multi-level process which is influenced by and itself influences its social and societal conditions. These conditions' impact on fertility behaviour requires, however, more extensive and explicit consideration in the next section.

Facing the critique of neglecting the concurrent multidimensionality and sequential self-referentiality of the life course, Ajzen and colleagues (Fishbein/Ajzen 2010; Ajzen/Klobas 2013) argue that the TPB does provide links to these features. Namely, previous behaviours or those induced by different intentions start feedback loops by serving as background factors which influence the beliefs preceding the fertility behaviour in question. In the very same vein, the TDIB accounts for life course features mainly through background factors which shape motivational traits (Miller) Pasta 1995).

The authors of the TCA have elaborated quite extensively on how past behaviours and behaviours with different intentions can influence fertility behaviour (Bachrach/Morgan 2013). Accordingly, the TCA considers past behaviours or behaviours induced by other notions as shaping a new base structure and mental schema. Thus, the modelled path to fertility behaviour starts anew as soon as the modelled path to another behaviour is completed. Temporally, these two processes can happen any time - separately as well as concurrently. Past behaviours, resources, and experiences can influence not only the material and schematic structure, but also the evolution of previously reasoned intentions into automatic schemas. Concurrent non-fertility behaviours can induce a situation in which fertility behaviour happens as an automatically processed by-product. In the full heuristic model, however, these elaborations are boiled down to an element of structure or only serve as background information. Thus, the authors of the TCA also refrain from explicitly modelling behaviours as products or by-products of other behaviours.

Utility-oriented approaches extensively cover self-referential processes underlying fertility behaviours, i.e. behaviours that are influenced by previous experiences and resources, at least in terms of the ideal embedding and succession of childbirth(s) (Gustafsson 2001). Less utilitarian experiences and resources are, however, neglected. Similarly, fertility behaviour as an outcome of other notions such as relationship maintenance is ignored completely because it bypasses rational and immediately intentional behaviour.

Thus, an explicit modelling of the concurrent multidimensionality of the life course is missing in all four models; sequential self-referentiality is mostly regarded as a loop in all models (save for utility-oriented approaches). The recognition of life courses' features is thus mainly in the hands of the researcher. In our view, however, a heuristic model of fertility should describe interconnections of behaviours more explicitly.

\section{Social and societal conditions}

The argument of social and societal conditions encompasses several influencing factors relevant to societies or social groups. Top down, these include, first, policies, economic conditions, and institutions, but also the historical and current context such as the development of reproductive technology. Second, fertility behaviour 
is embedded into a Leitbild, a cultural image of an ideal family, which also influences the interpretation of political and economic conditions (Schneider et al. 2015; Lück et al. 2017). For individuals, there may be several different Leitbilder in place, for instance, on the societal level, the regional level, within the own social group (Helfferich 2008), and on the level of a reference, role-model social group. Third, peers and relatives affect the fertility behaviour of both individuals and couples by serving as references for social learning, by exerting social pressure, by offering social support, and by acting as "vectors" for social contagions (Bernardi/Klärner 2014; Pink 2017). Of course, all these aspects are, in turn, shaped by the cumulated fertility behaviour of the individuals in questions, though that perspective exceeds the scope of this article.

The TPB covers the presented social and societal conditions by considering normative beliefs and social and institutional background factors (Fishbein/Ajzen 2010), though almost exclusively through the lens of social pressure. Furthermore, to account for macro-micro transmissions, recent research (Liefbroer et al. 2015) has embedded the TPB into a model inspired by Coleman (1990).

In contrast, the TDIB incorporates social and societal conditions far less explicitly. The personal value system which is conceptualised to influence desires acts as a mere proxy to a Leitbild, similar to the role of social networks as background factors in the formation of intentions and the implementation of behaviour (Miller) Pasta 1994, 1995; Miller et al. 2004). Thus, the TDIB lacks explicit links to social and societal conditions which, in our view, are crucial to fertility behaviour.

In the TCA, social and societal conditions, such as social networks, institutions, and Leitbilder, are considered as cognition-influencing material and schematic structures. The model correctly pays attention their interconnection and their cohesiveness as structure. In our view, it thereby offers the most promising approach in terms of accounting for social and societal conditions, though it achieves this by extracting only the very essence of the effects, and not the mode of operation.

In utility-oriented approaches, social and societal conditions are included rather ambivalently. Institutional and economic conditions influence the costs and benefits which behaviours entail and thereby shape considerations (e.g. Leibowitz et al. 1992). Normative conditions are included through the study of the social-normative value of children (Nauck 2014). The diffusion of behaviours through social networks, in contrast, is not included in utility-oriented approaches.

In sum, all models except for the TDIB offer one or two promising links to account for social and societal conditions' impact on fertility behaviour. Because of the complexity of the soci(et)al world, however, the models either miss aspects of the exerted influence or remain relatively vague.

\section{The body}

Another aspect for which heuristic models explaining fertility have been criticised is downplaying the role of the body. As mentioned earlier, this includes, on the one hand, sexual arousal and biology that can cause fertility behaviour to bypass intention (Barber 2011; Klobas 2011). On the other hand, an infertile body can hinder intentions and procreative behaviour from being transformed into a measurable out- 
come; the body acts as an "antagonist" to the goals of its bearer (Heimerl/Hofmann 2016). One main reason for the neglect is that while the heuristic models concern (pro- or contraceptive) behaviours, they are more often than not operationalised by measurable childbirth.

Ajzen and Klobas (2013) argue that these bodily aspects can be integrated in the TPB as outcomes of other behaviours with different intentions, i.e. as a lack of actual behavioural control. Once again, the advocates of the TPB argue that this is a question of the operationalisation and interpretation of the model: accommodating the body as an important element in fertility therefore lies solely in the responsibility of the researcher.

Similarly, the role of the body is included in the TDIB as a proxy at best. Though (perceived) fecundity has been considered in the TDIB (Miller/Pasta 1995, 2002), the body as a potential antagonist in translating behaviour into childbirth is limited. Similarly, the body as direct antecedent of behaviour, e.g. as host to sexual arousal, is neglected.

In the TCA and utility-oriented approaches, the body is completely ruled out as potential actor. The TCA does not raise the issue at all, whereas, in utility-oriented, especially economic approaches, infertility as a hindrance to fertility intentions runs contrary to the premise of actors' perfect information. Fertility behaviour as sideeffect of, for example, sexual arousal contradicts the notion that all behaviour is cognitively reasoned and controlled.

Thus, the body is rarely really accounted as a pro- or antagonist in fertility behaviour. In the addressed heuristic models, only TPB and TDIB offer links to allow for proxies. To some extent, it is not within the scope of the models because their aim is to explain behaviour, i.e. pro- or contraception or indifferent sexual behaviour. Since this behaviour is in most cases operationalised by the (more easily measurable) outcome of childbirth, however, a theoretical ignorance of the role of the body grossly neglects the body as important factor.

\subsection{Interim conclusion}

In sum, the four models vary greatly in their integration of the five aspects discussed above - the dyad of partners, unreasoned behaviour, the life course, social and societal conditions, and the body. Only the TDIB and utility-oriented approaches pay specific attention to the dyad of partners; only the TCA explicitly models unreasoned behaviour. The life course perspective is addressed in some ways by all four models, but a more explicit integration may contribute greatly to comprehending fertility behaviours. Societal conditions such as institutions and normative Leitbilder (cultural conceptions of family) are considered more or less explicitly in all four models. The impact of social networks beyond the argument of social pressure is, in contrast, only accommodated through proxies at best. Similarly, the body as a potential actor is merely reflected in control and perception proxies in TPB and TDIB.

As a consequence of this jigsaw puzzle of strengths and weaknesses, two or more of these models are regularly used concurrently in research to account for the 
relevant elements of fertility behaviour (Billari et al. 2009; Testa 2012; Balbo et al. 2013; Bernardi et al. 2015). As a result, researchers not only bear the responsibility to interpret the existing models and to laboriously translate their points of interest into proxies, but also to select and piece together full models or specific model elements, aiming to compensate for shortcomings and to balance their different foci. Therefore, the field of fertility research is varied and not necessarily a neat sequence of research questions and projects to answer them. A model that incorporates all relevant elements may be able to unify extant and future research.

\section{What we know from empirical research}

The discussed heuristic models closely guide quantitative research. On the one hand, they form the basis for survey construction (e.g. the TPB for the GGS, Vikat et al. 2007). As a result, the theoretically derived items pre-empt the replies of respondents and even their wording, thereby crucially impairing the reliability of the data (Barrett/Wellings 2002; Maher/Dever 2004). On the other hand, the heuristic models are consulted to formulate and operationalise hypotheses and to interpret results (e.g. Rosina/Testa 2009; Billari et al. 2009; Bauer/Jacob 2010; Balbo et al. 2013; Stein et al. 2014; Testa et al. 2014). Therefore, much quantitative fertility research is bound to replicate potential shortcomings of the heuristic models. Thus, in the following, we compile evidence, mainly from qualitative research, and identify the multilinear, complex pathways that have been found to factually precede fertility.

Some studies - mainly qualitative ones, but very few quantitative ones - address the issue of explaining fertility openly and from the research subjects' perspective, thereby fuelling the criticism directed at the presented heuristic models. Indeed, they find that the general desire to have children is not nearly as often the result of a big "lifestyle choice" as is commonly assumed (Rijken/Knijn 2009). Instead, a considerable share of respondents report that they could easily do without children - but could also be easily persuaded to have them, if, for instance, their partnership depended on it (Maher/Dever 2004; Rijken/Knijn 2009; Chen 2015). Furthermore, many reason their desires to have children not with excogitated arguments but with biological urges and intuition, with desires to repeat or ameliorate their own experiences, with a natural progression of their relationship, or with the feeling to be ready for the experience (Chen 2015). It is mainly people who are childless by choice and thus regularly confronted by society, who consciously reflect on their decision. But even in the decision of this select group, relational, instrumental, material, and career-orientated reasoning is of minor importance. Instead, they emphasise their biological and psychological disposition, their responsibility towards the potential child, as well as the experiences in their family of origin (Maher/Dever 2004; Maher et al. 2004; Chen 2015; also Hayford 2009). In fact, parenthood mostly seems to be so self-evident that, before the "right time" has actually come, even dyadic agreements stem from the communicative standard repertoire in the early relationship and nonverbal exchanges thereafter. Therefore, each partner's (particularly the man's) general desire to have children is rather a litmus test for the relationship; 
the actual question of having children is only due when (or if) one partner feels the "right time" has come and advances the conversation. If this conversation unveils discrepancies, the couple either breaks up, one partner waits for the readiness of the other, or accepts the concluding childlessness (Rijken/Knijn 2009; Chen 2015).

Thus, the more interesting question in fertility research is that of childbirth timing. In the life course, the ideal timing lies at the intersection of biological, psychosocial, relational, occupational, and intergenerational "right times" (Perrier 2013). Interestingly, biological constraints are relevant to all women and increasingly also to men. The interpretation of the female "biological clock" ranges between deadlines of approaching infertility and of approaching self-set age limits (Rijken/Knijn 2009). Analogically, men increasingly consider the age of 40 years to be a limit to an ideal, bodily fit and agile fatherhood (Maher et al. 2004; Rijken/Knijn 2009; Shirani 2013). Psycho-social aspects, in contrast, often limit the ideal childbearing years at the lower age range. Childbearing requires maturity, and maturity is a moving target encompassing completed personal fulfilment, a stabilised self, suitable living arrangements, and an inner readiness (Maher et al. 2004; Hobcraft/Kiernan 1995). Relationally, the ideal timing of childbearing requires a stable, lasting relationship with the right partner who is also at their "right time". At the same time, the timing is constrained occupationally by a completed educational and stable and adequate professional career. In this respect, however, educational groups may vary widely. For highly educated people, the prospect of a career itself serves as a kind of contraceptive (Perrier 2013): Rijken and Knijn (2009) observe that the very emergence of desires to have a child highly depends on the achievement of personal fulfilment and having established a satisfactory career. For less educated people, in contrast, early parenthood is a source of pride and social status which they might not achieve otherwise (Kağıtçıbaşı/Ataca 2005; Hayford 2009; Perrier 2013). Prior to childbirth, people with lower educational attainment hardly report any practical concerns; the desire and the readiness for a child are the main factors (Rijken/Knijn 2009). As a result, the less educated typically rearrange their life course and pursue an education and a career after family formation. The post-hoc rationalisation of feeling like they have not been at a professional disadvantage is supported by quantitative findings, which cannot find a consistent long-term career effect of the age at first birth (Duncan 2005; Brehm/Buchholz 2014; Putz/Engelhardt 2014). Arguably, the most important aspects to respondents is, however, the intergenerational "right time" which has been neglected somewhat in research. An intergenerationally ideal childbearing enables parents and children to enjoy many years together, it allows the grandparents to spend many healthy years with their grandchildren, and it maintains the possibility of the parents themselves enjoying their own grandchild later on (Perrier 2013). Obviously, these different "right times" counteract one another: Some strive for a fairly early childbirth, others seek to postpone it. As a result, the majority of childless people attribute their childlessness to not ever having found their personal "right time". Interestingly, they seldomly report regretting their resulting and eventually final delays (Maher et al. 2004).

As opposed to reconciling all these different "right times," however, between one quarter and half of all first births result from unplanned pregnancy (Maher et 
al. 2004; Schneider 2016). The reasons for women to carry these pregnancies out only rarely originate from their aversion for abortions, but rather from dyadic decision-making and a familiarisation with the facts (Maher/Dever 2004; Rijken/Knijn 2009; Chen 2015). Some respondents define such unplanned pregnancies as simultaneously wanted and unwanted because they generally want children, but not at the particular time or with the particular partner (Barrett/Wellings 2002). Some respondents even reject the idea of "planning" altogether when it comes to childbearing; particularly some men consider dealing with unexpected challenges when they occur as a reflection their masculinity (Barrett/Wellings 2002; Helfferich 2008; Rijken/Knijn 2009).

Following the first child, the intrinsic motivation to have a second is conventionally very high. Having an only child is associated with loneliness and selfishness in many cultures; respondents with only children often refer to external constraints, such as age, to deny responsibility for their choice (Chen 2015). The decisions for any further births beyond the second are then mostly made sequentially and ever more consciously, since the precise costs and reconciliation issues are known already. In fact, most mothers of three or more children do not identify as particularly motherly, but ascribe their sequential decisions to their reconcilable jobs and occupational opportunities, according to a study carried out in Australia. Beyond that, economic considerations are of less importance to parents of many children, they value the joy and love associated with a family more highly, and tend to reject idealised notions of motherhood (Maher et al. 2004; Chen 2015).

The short review of qualitative literature emphasises the validity of the five essential concepts for heuristic models to explain fertility. Though the review suggests that the dyad of partners, both well-reasoned and unreasoned behaviour, the life course, social and societal conditions, and the body all play a relevant part in fertility behaviour, the individual elements are hardly separable and require a considerable level of abstraction. For instance, the life courses of both partners and their social environment are tightly interconnected, and their reasoned or unreasoned cognitions can interact with "age and stage" in their life course. In order to develop a heuristic model, however, some abstractions must be made, albeit still allowing for complex interaction.

Furthermore, the review highlights that fertility behaviour does not follow a single heuristic model, but rather a variety of different pathways. For some people, conscious reasoning on childbirth in their stage of the life course plays a central role; others decide to have a child subconsciously to pursue their partnership; still others have an unplanned child. The pathways can differ between individuals, even between partners within one couple, as well as within individuals: the pathways to fertility typically differ by parity, but can even change due to new decisional framework conditions.

To meet the challenges of constructing a comprehensive model of fertility resulting from this variety of pathways, one must first understand the pathways themselves. In the literature, different pathways to fertility have now and again been addressed (Klobas 2011; Philipov 2011; Spéder/Kapitány 2015; cf. also Hakim 2000) or explicitly studied (Earle 2004; Hayford 2009; Bernardi et al. 2015). The identi- 
fied pathways therein are further supplemented by reports in qualitative interviews. Thus, the literature on pathways is multifaceted and its results are scattered. To obtain an overview of their variety, we compile the derivable pathways below. While the compilation attempts to be all-encompassing, it certainly does not claim to be so. Besides the theoretically most relevant and common "ideal-typical" pathway, the list is roughly ordered by eventual parenthood and its intentionality.

- "Ideal-typical": This is the pathway most other heuristic models target. The time is reasoned to be right or adjusted accordingly, and the pregnancy is intrinsically motivated and intended by both partners. The reasoned postponement of childbirth falls within this pathway (Earle 2004).

- "Early articulated childlessness": These individuals have been very certain of not wanting children early on, for reasons of perceived unsuitability to be parents or prioritisation of independence and personal fulfilment. This is an individual decision, but a decisive factor for a relationship (Maher et al. 2004; Hayford 2009; Bernardi et al. 2015).

- "Childless careerist": They prioritise their career over having children and thus want to remain childless for the sake of their career. This is an individual decision which is decisive for a relationship. The pathway is mainly substantiated by theoretical arguments (Hakim 2000).

- "Childless postponers": The "right time" to have children never arose, for reasons of psycho-social, relational, occupational, and, lastly, (perceived or real) biological constraints (Maher et al. 2004; Hayford 2009; Henwood et al. 2011; Bernardi et al. 2015).

- "Infertile": They are involuntarily childless for reasons of their (or their partners') insurmountable infertility or unsuccessful alternatives.

- "Infertile postponers": They (or their partners) struggle with conceiving or carrying the pregnancy full term. They overcome it eventually, but later than originally anticipated.

- "Late articulators": Their desire to have children is very strong, but comes relatively late in life; they worry about missing out on the last chance. Thus, their childbirth intention is a prerequisite to taking up or continuing a relationship, they communicate it clearly and forcefully (Rijken/Knijn 2009; Chen 2015).

- "Natural parents": They are highly family-oriented and aim for a (large) family early on. Thus, they pursue the first childbirth very early and sequential births soon after that (Hakim 2000; Hayford 2009).

- "Counter-ideal": Conditions are not ideal, but the intrinsic motivation to have children is so strong that they pursue childbirth anyway (Earle 2004).

- "Alternative role": Parenthood is a source of pride and social status. Thus, they don't consider practical challenges before pregnancy. Possibly, they consciously feel ready (Hayford 2009; Rijken/Knijn 2009; Perrier 2013).

- "Proceeders": They closely connect being in a long-term relationship with having children. A child is thus a natural continuation of their relationship, a legitimisation of their marriage, or a completion of their family (e.g. according to a two-child norm; Maher et al. 2004; Rijken/Knijn 2009; Chen 2015). 
- "Flexible": The individual is flexible or indifferent about having or not having a child; the decision is contingent upon the partner (Earle 2004; Rijken/Knijn 2009; Bernardi et al. 2015).

- "Laissez-faire": They consider a child welcome but not (yet) planned; they don't have any reason to use contraception, but no reason to actively pursue childbirth either (Earle 2004).

- "Sliders": Their pregnancy is unplanned or unintended, but upon acknowledging it, they adjust their conditions and mindsets to accommodate the child. Possibly, they reject abortions (generally or for themselves); otherwise, they might decide that the time is never right until you make it so (Earle 2004; Rijken/Knijn 2009; Chen 2015).

These pathways are abstract; it must be kept in mind that partners can individually follow different pathways which merge asymmetrically into a joint path. Also, the presented pathways differ in length: while some are spread out across several years, others take hold within days or weeks. Furthermore, individuals may follow a succession of different patterns themselves. Specifically, they may be stringed together by childbirths of different parities or by changes in dispositions, situations, or behaviours - for example, with regard to relationship stability, life plans, health and wellbeing, as well as structural or cultural conditions.

This literature review has shown that pathways to fertility are indeed multi-layered and multifaceted: Not all potentially relevant aspects always play a role in fertility behaviours; they differ in their prevalence, their strength and their timing of influence. If aspects do, however, play a role at all, disregarding them distorts the comprehensibility of fertility. Thus, the discrepancy between fairly unilinear heuristic models on the one hand and multi-path reality on the other is, first, theoretically implausible. Second, neglecting this variety of pathways is potentially detrimental to the results of empirical research: Analysing pooled pathways cannot differentiate overlays and, as a result, can lead to their empirical neutralisation or diminishment. It is therefore high time to establish a heuristic model that accounts for these different pathways to fertility.

\section{Towards a comprehensive fertility model}

The previous sections have shown that existing heuristic models of fertility fall short of explaining fertility in many respects, especially in terms of considering all relevant elements and allowing for the empirical variety of pathways preceding fertility. In the following section, we propose a heuristic model, the Model of Dyadic Pathways, which shall provide an integrative and thereby more realistic approach to fertility research. More specifically, the model aims, first, to be composed of the elements that have been suggested and found to matter, and, second, to incorporate all relevant pathways to fertility. In the following, we introduce the different layers of the model step by step. In doing so, we aim for better comprehension, not a hierarchically reasoned presentation. It is also crucial to understand that not all presented 
elements and processes are essential to fertility, but rather only potentially involved in the multilinear complex leading to childbirth.

\subsection{The composition of the Model of Dyadic Pathways}

The centre of our comprehensive fertility model, the Model of Dyadic Pathways (MDP), resembles Miller's and Pasta's $(1995,1996)$ TDIB, yet with one major difference. Instead of desires, it incorporates, more broadly, the motivational frame of each partner ( $f=$ female, $m=$ male) ${ }^{4}$ based on which each forms an actual intention to act. Mutually, they pursue a behaviour which precedes childbirth (Fig. 1).

By motivational frame, we mean a multifaceted element of partners' individual, intrinsic motivation regarding generally having or not having a child, childbirth timing, and the number of children: attitudes, values, preferences, personal Leitbilder (cultural conceptions of family), scripts, and desires. Potentially, these motivational frames can range on a continuum between child-positive and child-negative, they can be very dynamic and fluctuate between both poles, and they can be ambivalent, i.e. consist of both child-positive and child-negative motivational frames simultaneously (Miller/Pasta 2002; Barber et al. 2010). These motivational frames precede the intentions of both partners. Intentions, in turn, range on a scale between childpositive and child-negative but can be indifferent, too (Miller 2011).

The motivational frames and intentions of partners may - given their verbal or non-verbal communication - influence one another: on the one hand, we follow and extend the argument of Miller and colleagues (2004) that the motivational frame of each partner influences the other's as well as their own intention. On the other hand, we add reciprocal influences of partners' intentions. This, first, reflects the reports of some respondents that they themselves might be indifferent about having children but if their partner was not, they would agree to act according to the notion of their partner. This process clearly bypasses the (indifferent) motivational frame of one partner and arguably also a notable exchange about it since the child-positive person - knowing about the indifference of their partner - may reach out directly once the own intentions are set. Second, the intentions of one partner may be influenced by the other's due to their greater bargaining power. We will elaborate on this issue in greater detail below.

Furthermore, we add a direct connection between motivational frames and behaviour, bypassing the intentions. By doing so, we pay regard to what Earle (2004) calls a "laissez-faire pregnancy": A child is welcome, but neither intended nor unintended. There is, for example, no time squeeze yet, but no reasons to use contraception either. Thus, the motivational frame leads straight to the behaviour of the couple and, potentially, to a child.

Surrounding this core are elements required to understand fertility which influence, moderate, or bypass motivational frames and intentions which we will intro-

4 Aside from pathways that are premised on spontaneous fertilisation, the dyad is gender-unspecific. 
Fig. 1: $\quad$ The core of the Model of Dyadic Pathways

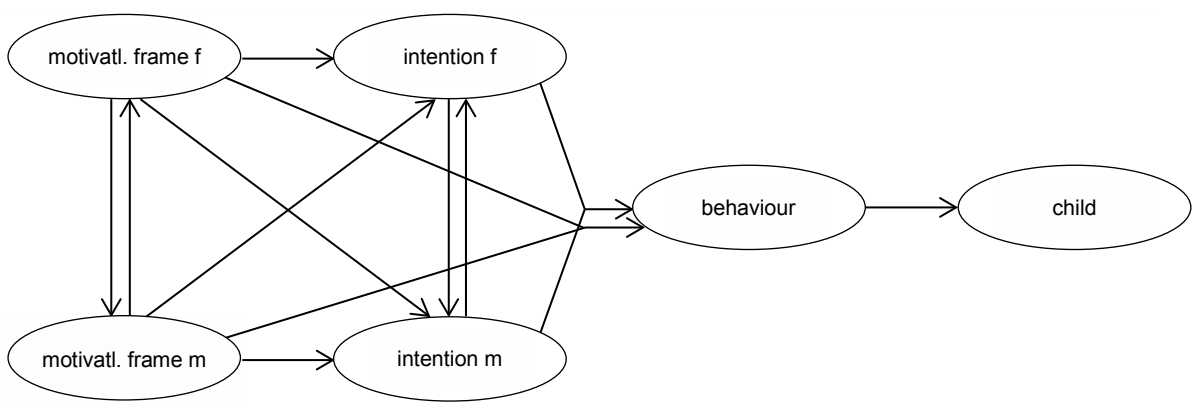

Source: own design

duce step by step in the following. In line with most existing heuristic models, a central element is conscious reasoning. It reflects on the benefits of having children on the one hand, which can be measured, for instance, using the Value of Children approach (Hoffman/Hoffman 1973; Nauck 2014), and the costs and opportunity costs of having children according to utility-oriented approaches on the other hand (Becker 1960; see also reasons for and against children in Langdridge et al. 2005). This reasoning exerts influence on the motivational frames of both partners as well as their intentions. Motivational frames are mostly shaped by partners' reasoning on the benefits of having children. If, for example, the personal or relational psychological utility of having children is assumed to be particularly positive, the motivational frames are child-positive, too - and vice versa (cf. Miller/Pasta 2002). In assumedly fewer cases, reasoning on (opportunity) costs contributes to suppressing motivational frames to have children. Intentions, in contrast, can be presumed to be the result of weighing all costs and benefits against one another - given that reasoning plays a role at all.

As seen from the qualitative research, however, there can be much more to motivational frames and intentions than reasoning. The life course in its concurrent multidimensionality and sequential self-referentiality plays a particular role in that regard - often in interaction with the conscious reasoning of a person. For example, the "right time" to have children is highly contingent upon the previous and current life course stage, but also on the anticipated future one. More specifically, the "right time" can be influenced by the resources and opportunities a person has accumulated over the life course. It can be shaped by previous and current experiences in the family of origin and particularly in the current relationship (including intimate behaviours) and the family composition (e.g. parity, gender, and health of previous children). Furthermore, the "right time" can be affected by living arrangements and occupational satisfaction, by the stage of personal fulfilment and maturation, and by the perception of a biological time squeeze (which, in our view, is principally distinct from the body since the time squeeze is mostly based on statistical perceptions or normative preferences). Additionally, ideas of the future can play a role, such as the anticipated parental role (e.g. being a fit, active, partaking parent and grandparent) 
or alternative life plans. The weights of reasoned arguments change and shift along these life course aspects, both with regard to (opportunity) costs and anticipated benefits. Thus, the interaction of reasoning and the life course exerts impact on each partner's motivational frame to have children as well as on their translation of it into an intention. Beyond that, the interaction of reasoning and the life course forms the individual bargaining power of each partner when it comes to differing intentions. At that point, one person might exert influence over the other, resulting in the intention of one partner affecting the other's, despite or against their differing motivational frames. In the model, this particular dyadic perspective is reflected in the two-way interchange between the intentions of both partners.

In addition to the impact exerted by the individual-level life course, we explicitly integrate the couple-level life course and the intersections of both levels. Thus, we build upon but go beyond the concept of "linked lives" (Elder 1994). The couplelevel life course covers aspects that only emerge and exist in the couple: the shared experiences of a couple, their joint resources and behaviours, common modes of interaction and communication, and unified schemes, meanings and notions. The couple-level life course is thus more than the sum of its parts. Furthermore, we argue that both individual-level life courses and the mutual couple-level life course influence one another in all directions. On the one hand, the two individual life courses reciprocally affect one another. On the other, the couple-level life course is shaped two-sidedly by the individual-level life courses and, in turn, reverberates back into them. This multifaceted life course complex shapes the motivational frames and intentions of both partners.

Beyond this, the life course complex may influence fertility behaviour directly, bypassing explicit motivational frames or intentions, let alone conscious reasoning. For example, an active sex life increases the chances of contraceptive failures - and so does lacking contraceptive knowledge or resources. Furthermore, upon having reached the right "age and stage" in both personal and relationship life, conscious perceptions of motivational frames and assessments of intentions may be bypassed; the life course exerts direct impact on behaviour. This is one way in which the previously proposed automatic cognition and unreasoned behaviour is reflected in the model.

As a result from the preceding elaborations, Figure 2 supplements the MDP's core with the interacting influences of reasoning on the one hand and the complex of individual-level (white) and couple-level (dark grey) life courses and their interactions on the other hand.

In a next step, we introduce the role of social and societal conditions - short: the soci(et)al world (cf. Fig. 3). As already established, the societal world in our definition includes macro level policies and institutions, the economy and the labour market, historical context and further influencing conditions such as the state of reproductive technology. Interrelated with these elements is the societal, social-group, or reference-group Leitbild as cultural conception of a family (Helfferich 2008; Schneider et al. 2015; Lück et al. 2017). On the micro level, the social world includes the influence of the social network, be it through social support, learning, pressure, or contagion (Bernardi/Klärner 2014). 
Fig. 2: The MDP's core with influences of conscious reasoning and the life course

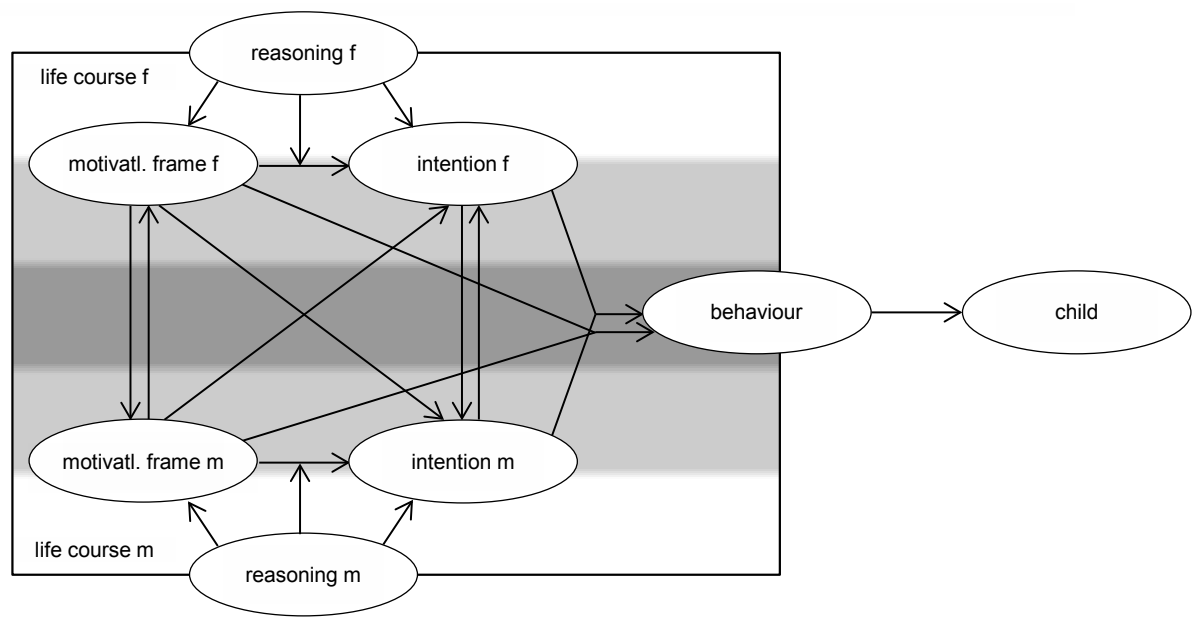

Source: own design

The soci(et)al world exerts its influence on fertility in manifold ways. A fairly straightforward way is the impact it has on reasoning, which has been paid more or less sufficient attention in existing models. For example, the assessment of the costs and benefits of having a child is framed and shaped by the current institutional, cultural and social contexts. Similarly, the life course is, in some ways, stamped by social and societal conditions, for instance when it comes to options of acquiring knowledge and resources, the typical progression of a life course, as well as perceptions of "ideal" prerequisites, timing, and family composition. This encompasses the assessment that parenthood is "part of the natural progression of [a] relationship" (Chen 2015: 83). As such, the soci(et)al world completes the triad that consists of an interaction of reasoning, the life course, and the soci(et)al world itself. The majority of exogenous impact factors of fertility originate from this triad: restrictions and opportunities, barriers and stimuli.

Beyond that, the soci(et)al world can directly influence motivational frames and intentions and even behaviour, though the boundaries are not always clear-cut. With regard to motivational frames, social and societal conditions contribute to whether having a child is a central aim in life, and to defining the identity of "mother" or "father". Debatably, we as social scientists would also subsume respondents' classification of such motivational frames to be "natural" and "intuitive" (Chen 2015) under the wide roof of "normativity". To understand the impact the soci(et)al world has on intentions and, similarly, behaviour, one ought to recall the public stir produced by Orna Donath's (2015) qualitative study about Israeli women "regretting motherhood". In that study, mothers stressed that if had it not been for normative expectations, they would not have had children - and might have been happier that way. Clearly, the motivation was not to have children, but rather to fit in or to live up to expectations. Childbearing intentions and behaviour thus bypassed the respective 
Fig. 3: $\quad$ The Model of Dyadic Pathways

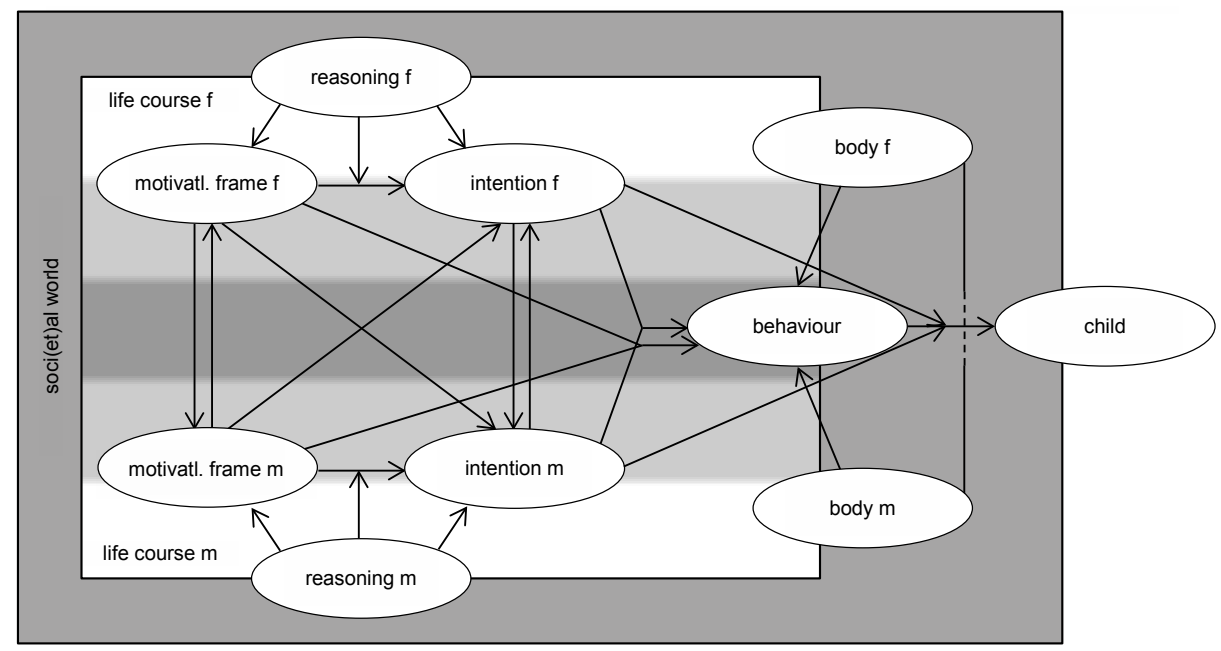

Source: own design

intrinsic motivational frame; possibly, the pathway might not even include intentions. On the contrary, the pathway is yet another way in which fertility behaviour might be the result of automatic cognition and unreasoned behaviour.

Lastly, the soci(et)al world itself can exert direct impact on the successful birth of a child. Depending on a society's or social group's technological and legal state, but also its infrastructure and its culture, pre- and perinatal medicine can or cannot work its wonders.

The final element required in a full heuristic model of fertility is, as we have argued, the body as a "teammate" or "antagonist" (Heimerl/Hofmann 2016; cf. Fig. 3). Its most obvious role is, first, to allow or hinder a pregnancy upon proceptive behaviour, depending on its fecundity or infertility. It thereby influences the connection between behaviour and childbirth. In this regard, the body itself can be influenced by other elements of the model, namely the life course and the soci(et)al world: Previous (health) behaviours and experiences can impair fertility. The technological, legal, infrastructural, and cultural state of a society or social group, in turn, can amplify or compensate for reproductive weaknesses of the body.

Second, the body can act as a catalyst for sexual arousal (Barber 2011). Thus, it might be a driver of behaviour itself, independent of any other behaviour-influencing element, let alone reasoning. As a consequence of such pathways which bypass clear intentions, a comprehensive Model of Dyadic Pathways furthermore needs to allow actors to either decide to have the child post-hoc, or to intervene, i.e. to abort. This is included in the MDP by drawing a connection between childbearing intentions and the pathway between behaviour and childbirth (which, formally, proceeds via exogenous, abortive behaviour). When abortion comes into play, however, the soci(et)al world gains a role, too: The normative or structural rejection of abortions 
can lead to childbirth, even though peoples' motivational frame, reasoning and life course might demand the opposite. This decision is likely to cross intentions, but it might also bypass them and connect the soci(et)al world directly to (passive) behaviour, e.g. when norms are so deeply rooted in a person that abortion is, in fact, unthinkable.

\subsection{Different pathways to fertility}

Differently from most other models, the proposed heuristic Model of Dyadic Pathways covers a multitude of pathways to fertility. Some of them have been addressed to explain the model composition. The literature review in the last section, however, suggests many more pathways (cf. pages 16-17). To exemplify the properties of the model, we select three typical or particularly interesting dyadic pathways and describe their progression through the model. Namely, we chose (1) an "ideal-typical" well-reasoned dyadic pathway, (2) a union of a "flexible," i.e. child-indifferent, and a "counter-ideal" partner who is child-positive against all odds, as well as (3) the pathway of "sliders" who become pregnant without any prior intrinsic motivation, let alone intention. To characterise these pathways and their reflection in the MDP, we disassemble the comprehensive model and emphasise only the elements and connections which are relevant to the respective pathway.

The "ideal-typical" pathway to fertility

The "ideal-typical" pathway to fertility is illustrated in Figure 4. According to this pathway, both partners communicate their motivational frames; the exchange mutually influences their motivational frames and intentions. Both elements are, furthermore, the result of a reasoning on (opportunity) costs and benefits, such as the

Fig. 4: The "ideal-typical" pathway to fertility

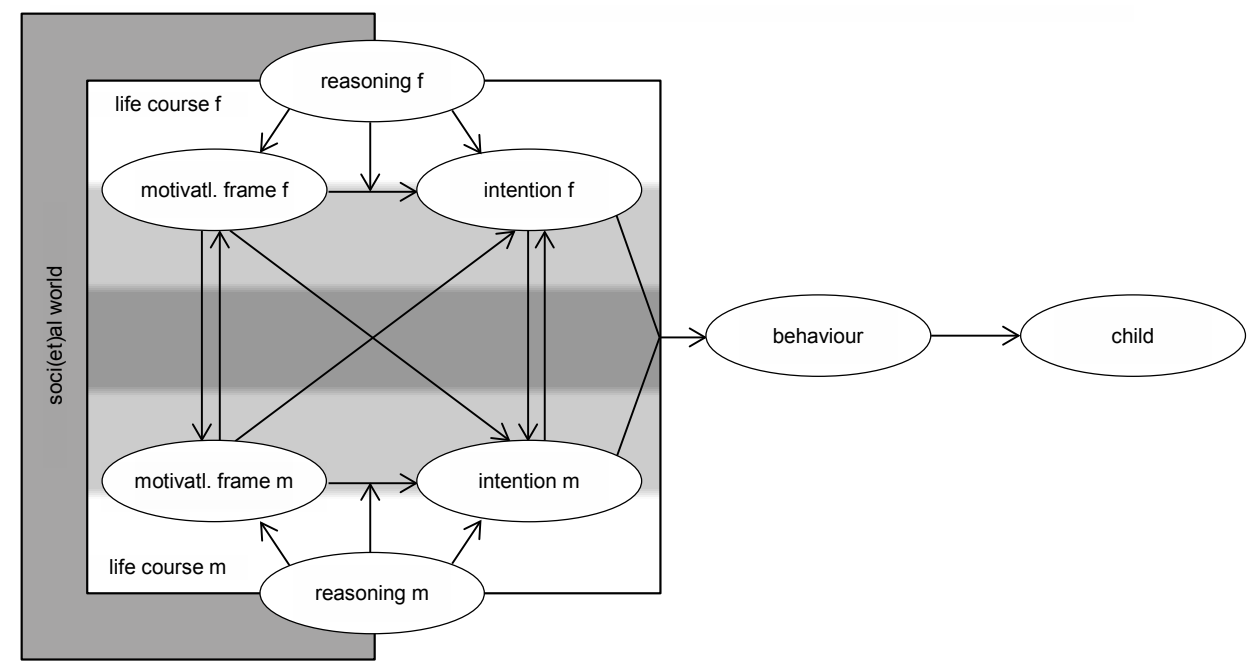

Source: own design 
assumed value of children, in interaction with their specific stage in the life course, including their educational and occupational maturation, their completed adolescent self-fulfilment, the suitability of living arrangement, their intergenerational position, and, of course, their stable and satisfactory relationship. This reasoning on the "right time" translates motivational frames into intentions. The soci(et)al world exerts its impact on the motivational frames of both partners, e.g. the desirability of parenthood and a parent identity, as well as their reasoning (e.g. on the nature and weight of costs and benefits) and the life course (e.g. the normative requirements to reaching the "right time," the role of the intergenerational "right time").

Upon forming intentions, both partners jointly pursue proceptive behaviour which soon translates into a successful pregnancy. The body acts as a "team player" instead of an antagonist and does not require further attention.

\section{The pathway of one "flexible" and one "counter-ideal" partner}

Figure 5 exemplifies the seemingly simple pathway of a couple of one "counter-ideal" and one "flexible" partner. Strikingly, the soci(et)al world, conscious reasoning, and the life course do not play a role for either of the partners. For the "counterideal" partner, this reflects that the strong child-positive motivational frame and particularly its translation into an intention occur irrespective of any constraints. The child positivity is so strong that the partner pursues a proceptive behaviour irrespective of normative or social boundaries, irrespective of any reasoned cost-benefit analysis, and irrespective of any timing concerns in the light of the life course. The "flexible" partner, on the other hand, is not influenced by these elements. He (in our example, it is a man) does not show any motivational frame on his own and his intentions are completely and unidirectionally preceded by the motivational frames and intentions of his partner. As a result, they act jointly, which, again, unimpededly leads to a pregnancy.

Fig. 5: The pathway of a "flexible" and a "counter-ideal" partner

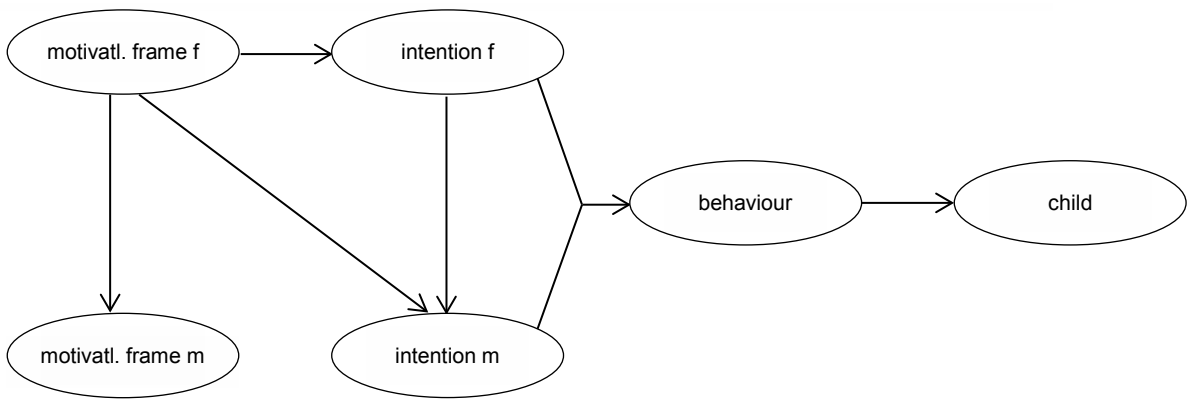

Source: own design 
Fig. 6: The pathway of "sliders"

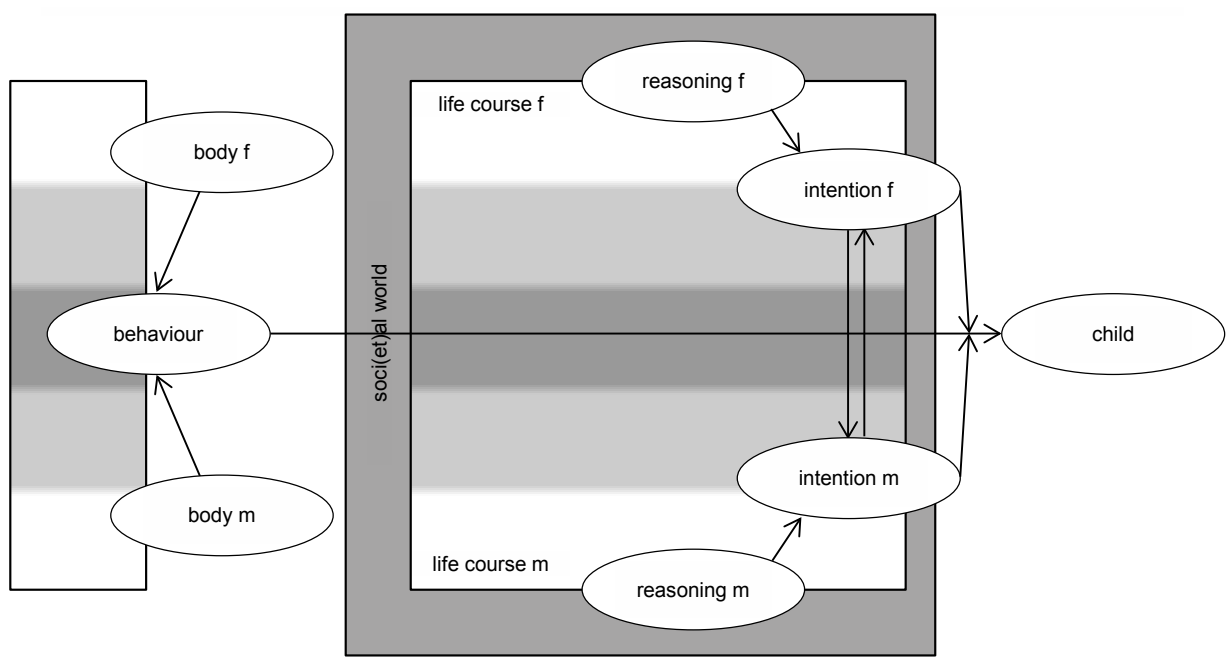

Source: own design

\section{The pathway of "sliders"}

In Figure 6, we illustrate a couple that has no intrinsic motivation or intention to become pregnant, but rather "slides into" parenthood following a pregnancy that results from an active intimate life. The pathway exemplifies ways in which the MDP can convey processes that do not follow the linear path of decisions preceding behaviours. Instead, "sliders" illustrate how the MDP can be dis- and reassembled without breaking its general structure. For better readability, we have relocated the impregnating behaviour and its direct antecedents to the left-hand side of Figure 6, while the decision-making process to keep the child is moved between behaviour and childbirth. By simply swapping the behavioural for the decision-making complex, one would retain the original shape of the MDP.

Since the pregnancy of sliders occurs as a by-product of an active intimate life rather than as the result of a decision-making process, the life course makes its first appearance on the left-hand side of Figure 6. Possibly, the influence of the life course originates from partners' lack of contraceptive knowledge or, on the contrary, their knowledge of the relatively small odds of becoming pregnant per ovarian cycle and therefore taking a chance (even under ideal conditions, only up to 35 percent of women become pregnant; Gnoth et al. 2005). This situation is further fuelled by sexual arousal that defeats further reasoning. As a result, the behaviour and the pregnancy are, in this example, antecedents to the intention-building of partners.

Following the discovery of the pregnancy, the partners enter the likely difficult conversation about how to proceed (Chen 2015). It is only at that stage, on the righthand side of the model, that cost-benefit reasoning in interaction with life course assessments and soci(et)al influences, such as the assurance of social support or the normative rejection of an abortion, contribute to the pathway. As a result, the actual 
conscious fertility decision is made by not aborting the child but carrying the pregnancy full term, i.e. by continuing the connection between behaviour and childbirth.

This pathway can plausibly also be asymmetrical. This would apply in cases in which the "sliding" does not occur in a romantic long-term relationship but in a mainly sexual short-term one. In these instances, the decision-making process would be predominantly on the part of the woman, possibly even without any male contribution. Hence, the lower half of the decision-making process would be empty, and the life course would, of course, be only relevant on the individual level.

\subsection{Interim conclusion}

In the previous section, we presented our Model of Dyadic Pathways and its properties with regard to comprehending a number of widely differing pathways to fertility. Our presentation outlined, first, how only a complex and multi-layered model can truly explain the great variety of dyadic processes to having a child. Second, we demonstrated how the full model must be disassembled reflectively in order to accommodate and distinguish the pathway variety which, if pooled, may veil weaker trajectories, neutralise opposing ones, and even suggest sequences of steps that do not align with reality.

Beyond these technical properties, the MDP succeeds in incorporating a number of real-life peculiarities of pathways to fertility. First, it accounts for the dyad of two individuals which potentially have very distinct motivations, notions, and decisional processes that lead to childbirth. The MDP allows for asymmetrical dyadic trajectories that merge into a joint pathway. Second, the MDP is, like reality, dynamic and flexible. It is open to linear as well as to swaying decisional processes, to neatly aligned pathways of high and low speeds as well as to detours, roundabouts, and dead ends. Third, the MDP integrates not only variability between couples and between individuals, but also within individuals. For example, fertility pathways can differ widely for child parities one, two and three: the first child marks the substantial transition to being a family; the second child pursues the normative ideals; the third child is unplanned or, on the contrary, consciously planned in full knowledge of what goes with it. Similarly, fertility pathways can also vary between relationships: a new partner can imply a completely different set of individual- and couple-level life courses, of arguments in reasoning, of social conditions. But even less obvious incisions than childbirths and new partnerships can redirect pathways to fertility: occupational or personal reorientation, health issues or diagnoses, societal changes - to name only a few. Along these lines, the MDP captures the complex, dynamic, and multidimensional nature of fertility in a single model.

\section{The MDP's contributions and challenges to fertility research}

In the previous sections, we have measured prevailing heuristic models against unpre-empted evidence and, hence, identified several blind spots of the TPB, the TDIB model, the TCA, and utility-oriented approaches. As an integrative alternative, we 
have suggested the Model of Dyadic Pathways, and have elaborated on its features and utilities. In the following, we will locate the MDP in existing fertility research by accentuating its contributions and by assessing the challenges to successfully applying it to fertility research.

\subsection{Contributions}

The MDP's contribution to fertility research is threefold: first, its comprehensive perspective on fertility explicitly prompts researchers to take into account all relevant antecedents of fertility. It thus challenges fertility research to move beyond researchers' selective employment of heuristics, their subjective interpretation of proxies, and different research traditions. Instead, the Model of Dyadic Pathways offers a single comprehensive heuristic to understand fertility. At the same time, it offers links to theories of decision-making and action theories. In fact, it prompts their integration, including their differences regarding pathway premises and behavioural logics. The MDP thereby systematically facilitates the simultaneous testing of hypotheses and counter-hypotheses, enabling scientific advancement.

Second, the MDP reintegrates and connects existing, partly widely varying strands of fertility research. Due to different foci and traditions, findings in fertility research are often highly diversified and scattered. The Model of Dyadic Pathways explicates the multifaceted interconnections between these strands. It thereby combines their individual yet complementary and interactive contributions to a conjoint picture to understand fertility. This way, it also exposes missing links to understanding fertility in its complexity, and offers guidance in areas researchers have not yet explored.

Third, it integrates the multitude of different pathways of fertility. Inductive research has shown that fertility can be the result of a wide variety of reasons, conditions, and behaviours. Explaining it against the backdrop of a single, linear heuristic model therefore necessarily neglects, veils, or even overwrites relevant pathways to fertility. The Model of Dyadic Pathways, in contrast, prompts their separate acknowledgement and analysis, enabling an assessment of the composition and relevance of each pathway.

\subsection{Challenges}

Finding the novel pathways described in the MDP, however, crucially depends on the data and thus, in a very first step, on the operationalisation of the model's elements. This poses a fundamental challenge to research, particularly to survey methodology. While many of the model's requirements are met in existing surveys and datasets, many other operationalisations are inadequate, outdated, or only occasionally represented at all. Some criticism has already been voiced by the scientific community. In the following, we broadly contour and respond to the critique.

The focus on dyads is central not only to our MDP but to fertility research in general. To understand fertility, it is crucial to understand partners and their interaction, their similarities, disagreements, and conflicts. Eight to fourteen per cent of 
couples report differing family plans, a surprisingly low number (Testa et al. 2011; Kuhnt 2013). These relatively small numbers may indeed reflect reality, or may be the result of measurement biases such as broad-brush questions or forced dichotomisation. Either way, it is worth examining through which pathways partners in disagreement pursue their plans, if and how they differ in their pathway structures, their relevant elements, and what it takes to reconcile their approaches.

When it comes to actual questions, qualitative studies suggest that many of the established, sometimes decades-old questionnaire items anticipate the answers of the respondents. Beyond that, they are often too simplistic in view of the complexity of fertility, and also in view of the heterogeneity of respondents. Thus, to obtain reliable items, it would be worthwhile to take a step back: There is much promise in utilising existing qualitative studies or in conducting targeted new ones as the basis for survey construction.

In some respect, the necessary reform of questionnaires is already underway, with a new elicitation of motivational frames, intentions and behaviour at the vanguard. With regard to motivational frames, proposals include two unipolar scales to allow for simultaneous child-positive and child-negative desires (Miller 2011), inquiries about several preferences regarding the anticipated number of children (Maher et al. 2004; Chen 2015), and the operationalisation of a sequential "discovery" of the final number of children since it is often a residual from sequential and dyadic reconcilement after each child (Ní Bhrolcháin/Beaujouan 2015). Beyond that, the Leitbild approach (Schneider et al. 2015; Lück et al. 2017) recommends individual ideals concerning the image of a family, and scripts to mothering and fathering. The operationalisation of intentions, in contrast, should be clearly distinguishable from items measuring desires (Testa 2012). Furthermore, Barber and colleagues (2010) suggest asking people both how much they want to have children and how much they want to avoid them. On all accounts, it is most relevant to also assess how each person perceives the motivational frame and intention of her/his partner and identify the impact on their own notions (Miller et al. 2004). With regard to behaviour, questionnaires need to allow not only for contraception and proception, but also for laissez-faire behaviour.

In another vein, it is necessary to allow motivational frames and intentions to change over the course of time. This goes beyond the well-known fact that intentions lose their sharpness the further the anticipated decision is in the future (Morgan 1985). The matter is of particular interest in observing dyads: although respondents firmly endorse gender equality when it comes to having a say in reproduction, women are granted more decision-making power in the case of dissonances (Chen 2015). This seeming contradiction is just one of many that deserve further attention in the pathways to fertility.

Reasoning as one framing condition that leads to fertility behaviour is well covered in existing surveys - though the selection of questionnaire items is often driven by theoretical considerations (e.g. (opportunity) costs: Becker 1960; Value of Children: Nauck 2014) rather than by verified influential ones (cf. reasons for and against having a child: Langdridge et al. 2005). Unreasoned behaviour remains widely understudied and -measured in this respect. To unveil unreasoned pathways, $\mathrm{Ba}$ - 
chrach and Morgan (2013) suggest focusing on underlying mental schemas. We would add that surveys should explicitly allow for alternative routes driven by life course events, normative notions, and bodily factors. Furthermore, it might be feasible to inquire directly after the actual role of practical or emotional reasoning in individual fertility and to what extent people consciously reflect on their desires, intentions, and behaviours at all. Hitherto, quantitative fertility research depends on a number of bridge hypotheses that attribute reasoning to fertility decisions. However, qualitative research implies that these bridges are not built on firm ground.

To understand the impact of the life course, we recommend paying detailed attention to both individual-level and couple-level life courses, and their interaction. In terms of individual-level life courses, we suggest operationalising concurrent trajectories, as well as the individual "age and stage" and anticipated future. This concerns, for example, their psycho-social state, including their reproductive knowledge and beliefs, their professional standing, their intergenerational notions, their perceived biological conditions, and, lastly, their relational life courses (cf. details in section 3). The latter overlaps with the couple-level life course which requires particular attention. It represents the shared relationship of the couple, their previous and anticipated biography, the joint resources and reciprocity, and the unified behaviour, interaction, notions, and meanings.

Beyond that, the impact of the soci(et)al world on fertility pathways deserves further attention. While structural conditions are usually easily identified, the cultural and normative framework is mostly imputed from the knowledge of researchers. As a substitute to mere imputations, a concept such as the Leitbild (Schneider et al. 2015; Lück et al. 2017) would benefit our understanding immensely by measuring cultural conceptions of family on the societal, social-group, and reference-group level. Questions about family ideals and beliefs deserve further probing with questions about what relationship progression, sexuality and measures of family planning respondents consider "normal" and "right" (cf. Helfferich 2008). Similarly, with all we know about influences of social learning, contagion, pressure, and support, these aspects deserve systematic operationalisation in surveys. This incorporates collecting data on, for example, fertility and support in the wider social network.

Lastly, a quite underrepresented yet pivotal actor to understand fertility is the body (Heimerl/Hofmann 2016). Thus, on the one hand, we need to extend our knowledge about sexual arousal which overrules intentions to use contraception. Research on discrepancies between child intentions and contraceptive behaviour shows that there are blind spots which are yet to be examined and systematised (e.g. Sass/er et al. 2009). Similarly, we need data on people's actual struggles with the wide range of infertility, both acutely and as a process, with regard to personal perceptions (on the individual and couple level) as well as true biological barriers. In fact, the perception of infertility depends on respondents' exposure, the rate at which observations enter their consciousness, and individual problematisation. The clinical diagnosis of infertility also involves a long, dyadic process bristling with uncertainties, and is accompanied by a wide variety of medical treatments and advice (cf. Johnson/Johnson 2008; Passet-Wittig et al. 2018). 
Once the Model of Dyadic Pathways is, in a first step, supported by reliable and thorough panel data, the identification and comprehension of pathways to fertility, as a second step, is feasible. This particular strength of the Model of Dyadic Pathways is, at the same time, a particular challenge to empirical application. Different from linear models, the multilinear MDP requires researchers to delve more profoundly into the research issue and into its measurement. As the very basis to any analysis, researchers are tasked with identifying the relevant pathways in a specific sample. This requires a targeted analysis of tightly clocked panels (Barber et al. 2010 argue for a weekly survey) which reflect the described elements of the model. The identification of pathways is undoubtedly a most interesting one as it can be expected to offer valuable insight into processes, associations, and causalities leading to fertility. The most suitable methodology to facilitate this step is, however, yet to be identified by the research community. But with recent developments in longitudinal methods, such as sequence and cluster analysis, we are confident that an appropriate or suitably adapted methodology is on the horizon.

Thereafter, in a third step, researchers are encouraged to seize these pathways as variables in their respective research questions and methodologies. For example, pathways can be employed as dependent variables for historic, international, or structural and cultural comparisons, as well as for group-specific analyses regarding education and migration background. And since the underlying MDP aims for comprehensiveness, chances are that it offers means to surpass the hitherto mediocre explanation of variation in fertility outcomes.

\section{References}

Ajzen, Icek 1991: The Theory of Planned Behavior. In: Organizational Behavior and Human Decision Processes 50,2: 179-211.

Ajzen, Icek 2011a: Reflections on Morgan and Bachrach's Critique. In: Morgan, S. Philip; Sobotka, Tomáš; Testa, Maria Rita (Eds.): Reproductive Decision-Making. Vienna Yearbook of Population Research 9. Vienna: Verlag der Österreichischen Akademie der Wissenschaften: 63-69 [doi: 10.1553/populationyearbook2011s63].

Ajzen, Icek 2011b: The Theory of Planned Behaviour. Reactions and Reflections. In: Psychology and Health 26,9: 1113-1127 [doi: 10.1080/08870446.2011.613995].

Ajzen, Icek 2014: The Theory of Planned Behaviour is Alive and Well, and not Ready to Retire. A Commentary on Sniehotta, Presseau, and Araújo-Soares. In: Health Psychology Review 9,2: 131-137 [doi: 10.1080/17437199.2014.883474].

Ajzen, Icek; Klobas, Jane E. 2013: Fertility Intentions. An Approach Based on the Theory of Planned Behavior. In: Demographic Research 29,8: 203-232 [doi: 10.4054/DemRes.2013.29.8].

Bachrach, Christine A.; Morgan, S. Philip 2013: A Cognitive-Social Model of Fertility Intentions. In: Population and Development Review 39,3: 459-485 [doi: 10.1111/j.17284457.2013.00612.x]. 
Balbo, Nicoletta; Billari, Francesco C.; Mills, Melinda 2013: Fertility in Advanced Societies: A Review of Research: La fecondite dans les societes avancees: un examen des recherches. In: European Journal of Population 29,1: 1-38 [doi: 10.1007/s10680-0129277-y].

Barber, Jennifer S. 2011: The Theory of Planned Behaviour. Considering Drives, Proximity and Dynamics. In: Morgan, S. Philip; Sobotka, Tomáś; Testa, Maria Rita (Eds.): Reproductive Decision-Making. Vienna Yearbook of Population Research 9. Vienna: Verlag der Österreichischen Akademie der Wissenschaften: 31-35 [doi: 10.1553/populationyearbook2011s31].

Barber, Jennifer S.; Kusunoki, Yasamin; Gatny, Heather 2010: Design and Implementation of an Online Weekly Survey to Study Unintended Pregnancies. Preliminary Results. Research Report. Michigan.

Barrett, Geraldine; Wellings, Kaye 2002: What is a 'Planned' Pregnancy? Empirical Data from a British Study. In: Social Science \& Medicine 55: 545-557.

Bauer, Gerrit; Jacob, Marita 2010: Fertilitätsentscheidungen im Partnerschaftskontext. In: Kölner Zeitschrift für Soziologie und Sozialpsychologie 62,1: 31-60 [doi: 10.1007/ s11577-010-0089-y].

Becker, Gary S. 1960: An Economic Analysis of Fertility. In: National Bureau of Economic Research (NBER) (Ed.): Demographic and Economic Change in Developed Countries. A Conference of the Universities-National Bureau Committee for Economic Research. Special Conference Series 11. New York: Columbia University Press: 225-256.

Becker, Gary S. 1991: A Treatise on the Family. Cambridge (MA): Harvard University Press.

Becker, Gary S.; Lewis, Gregg H. 1973: On the Interaction between the Quantity and Quality of Children. In: Journal of Political Economy 81,2: 279-288.

Bernardi, Laura; Klärner, Andreas 2014: Social Networks and Fertility. In: Demographic Research 30,22: 641-670 [doi: 10.4054/DemRes.2014.30.22].

Bernardi, Laura; Mynarska, Monika; Rossier, Clémentine 2015: Uncertain, Changing and Situated Fertility. A Qualitative Analysis. In: Philipov, Dimiter; Liefbroer, Aart C.; Klobas, Jane E. (Eds.): Reproductive Decision-Making in a Macro-Micro Perspective. Dordrecht: Springer: 113-139 [doi: 10.1007/978-94-017-9401-5_5].

Billari, Francesco C.; Philipov, Dimiter; Testa, Maria Rita 2009: Attitudes, Norms and Perceived Behavioural Control. Explaining Fertility Intentions in Bulgaria. In: European Journal of Population 25,4: 439-465 [doi: 10.1007/s10680-009-9187-9].

Breen, Richard; Goldthorpe, John H. 1997: Explaining Educational Differentials. Towards a Formal Rational Action Theory. In: Rationality and Society 9,3: 275-305 [doi: 10.1177/104346397009003002].

Brehm, Uta; Buchholz, Sandra 2014: Is there a Wrong Time for a Right Decision? The Impact of the Timing of First Births and the Spacing of Second Births on Women's Careers. In: Journal of Family Research 26,3: 269-301 [doi: 10.3224/zff.v26i3.18989].

Chen, Zhong Eric 2015: Fertility Decision-Making. A Qualitative Study in Scotland. Edinburgh: The University of Edinburgh.

Coleman, James S. 1990: Foundations of Social Theory. Cambridge (MA): Belknap.

Corijn, Martine; Liefbroer, Aart C.; de Jong Gierveld, Jenny 1996: It Takes Two to Tango, Doesn't It? The Influence of Couple Characteristics on the Timing of the Birth of the First Child. In: Journal of Marriage and Family 58,1: 117-126 [doi: 10.2307/353381]. 
Dommermuth, Lars; Klobas, Jane E.; Lappegård, Trude 2015: Realization of Fertility Intentions by Different Time Frames. In: Advances in Life Course Research 24: 34-46 [doi: 10.1016/j.alcr.2015.02.001].

Donath, Orna 2015: Regretting Motherhood. A Sociopolitical Analysis. In: Signs: Journal of Women in Culture and Society 40,2: 343-367 [doi: 10.1086/678145].

Duncan, Simon 2005: What's the Problem. Teenage Parents a Critical Review. Working Paper.

Earle, Sarah 2004: 'Planned' and 'Unplanned' Pregnancy. Deconstructing Experiences of Conception. In: Human Fertility 7,1: 39-42 [doi: 10.1080/1464727042000198078].

Ekert-Jaffé, Olivia et al. 2002: Fertility, Timing of Births and Socio-Economic Status in France and Britain. Social Policies and Occupational Polarization. In: Population 57,3: 475-508 [doi: 10.2307/3246636].

Elder, Glen H. 1994: Time, Human Agency, and Social Change. Perspective on the Life Course. In: Social Psychology Quarterly 57,1: 4-15 [doi: 10.2307/2786971].

Esser, Hartmut 1996: Die Definition der Situation. In: Kölner Zeitschrift für Soziologie und Sozialpsychologie 48,1: 1-34.

Fishbein, Martin; Ajzen, Icek 2010: Predicting and Changing Behavior. The Reasoned Action Approach. New York/Hove: Psychology Press.

Gnoth, Christian et al. 2005: Definition and Prevalence of Subfertility and Infertility. Debate - Continued. In: Human Reproduction 20,5: 1144-1147 [doi: 10.1093/humrep/ deh870].

Gustafsson, Siv 2001: Optimal Age at Motherhood. Theoretical and Empirical Considerations on Postponement of Maternity in Europe. In: Journal of Population Economics 14,2: 225-247 [doi: 10.1007/s001480000051].

Hakim, Catherine 2000: Work-Lifestyle Choices in the $21^{\text {st }}$ Century. Preference Theory. Oxford: Oxford University Press.

Hayford, Sarah R. 2009: The Evolution of Fertility Expectations over the Life Course. In: Demography 46,4: 765-783 [doi: 10.1353/dem.0.0073].

Heimerl, Birgit; Hofmann, Peter 2016: Wie konzipieren wir Kinderkriegen? Normativer Rationalismus versus empirische Praxisforschung. In: Zeitschrift für Soziologie 45,6: 410-430 [doi: 10.1515/zfsoz-2015-1024].

Helfferich, Cornelia 2008: Reproduktive Kulturen. Die Regeln des angemessenen Umgangs mit Fertilität, reproduktiven Technologien und Geschlechterbeziehungen im Lebenslauf. In: Rehberg, Karl-Siegbert; DGS (Eds.): Die Natur der Gesellschaft. Verhandlungen des 33. Kongresses der Deutschen Gesellschaft für Soziologie in Kassel 2006. Frankfurt am Main: Campus: 441-454.

Henwood, Karen; Shirani, Fiona; Kellett nee Procter, Joanne 2011: On Delayed Fatherhood. The Social and Subjective "Logics" at Work in Men's Lives (a UK Study). In: Beets, Gijs; Schippers, Joop; te Velde, Egbert R. (Eds.): The Future of Motherhood in Western Societies. Late Fertility and its Consequences. Dordrecht/New York: Springer: 159-175 [doi: 10.1007/978-90-481-8969-4_11].

Hobcraft, John; Kiernan, Kathleen 1995: Becoming a Parent in Europe. European Population Conference: Milano.

Hoffman, Lois Wladis; Hoffman, Martin L. 1973: The Value of Children to Parents. In: Fawcett, James T. (Ed.): Psychological Perspective on Population. New York: Basic Books: 19-76. 
Jansen, Miranda; Liefbroer, Aart C. 2006: Couples' Attitudes, Childbirth, and the Division of Labor. In: Journal of Family Issues 27,11: 1487-1511 [doi: 10.1177/0192513X06291038].

Johnson, Katherine M.; Johnson, David R. 2008: Partnered Decisions? U.S. Couples and Medical Help-Seeking for Infertility. In: Family Relations 58,4: 431-444 [doi: 10.1111/j.1741-3729.2009.00564.x].

Johnson-Hanks, Jennifer A. et al. 2011: Understanding Family Change and Variation. Toward a Theory of Conjunctural Action. Dordrecht: Springer [doi. 10.1007/978-94007-1945-3].

Kağıtçıbaşı, Çiğdem; Ataca, Bilge 2005: Value of Children and Family Change. A ThreeDecade Portrait from Turkey. In: Applied Psychology 54,3: 317-337 [doi: 10.1111/j.14640597.2005.00213.x].

Klein, Thomas; Eckhard, Jan 2007: Educational Differences, Value of Children and Fertility Outcomes in Germany. In: Current Sociology 55,4: 505-525 [doi: 10.1177/0011392107077636].

Klobas, Jane E. 2011: The Theory of Planned Behavior as a Model of Reasoning about Fertility Decisions. In: Morgan, S. Philip; Sobotka, Tomáš; Testa, Maria Rita (Eds.): Reproductive Decision-Making. Vienna Yearbook of Population Research 9. Vienna: Verlag der Österreichischen Akademie der Wissenschaften: 47-54 [doi: 10.1553/populationyearbook2011s47].

Klobas, Jane E.; Ajzen, Icek 2015: Making the Decision to have a Child. In: Philipov, Dimiter; Liefbroer, Aart C.; Klobas, Jane E. (Eds.): Reproductive Decision-Making in a Macro-Micro Perspective. Dordrecht: Springer: 41-78 [doi: 10.1007/978-94-017-9401-5_3].

Kuhnt, Anne-Kristin 2013: Ja, nein, vielleicht? Die Einfluss der Parnerschaftsqualität auf die Übereinstimmung der Elternschaftsabsichten von Paaren. In: Journal of Family Research 25,3: 365-388.

Kuhnt, Anne-Kristin; Trappe, Heike 2013: Easier Said than Done. Childbearing Intentions and their Realization in a Short Term Perspective. MPIDR Working Paper. Rostock.

Langdridge, Darren; Sheeran, Paschal; Connolly, Kevin 2005: Understanding the Reasons for Parenthood. In: Journal of Reproductive and Infant Psychology 23,2: 121-133 [doi: 10.1080/02646830500129438].

Leibenstein, Harvey 1974: An Interpretation of the Economic Theory of Fertility. Promising Path or Blind Alley? In: Journal of Economic Literature 12,2: 457-479.

Leibowitz, Arleen; Klerman, Jacob Alex; Waite, Linda J. 1992: Employment of New Mothers and Child Care Choice. Differences by Children's Age. In: The Journal of Human Resources 27,1: 112-133.

Liefbroer, Aart C. 2011: On the Usefulness of the Theory of Planned Behavior for Fertility Research. In: Morgan, S. Philip; Sobotka, Tomáš; Testa, Maria Rita (Eds.): Reproductive Decision-Making. Vienna Yearbook of Population Research 9. Vienna: Verlag der Österreichischen Akademie der Wissenschaften: 55-62 [doi: 10.1553/populationyearbook2011s55].

Liefbroer, Aart C. et al. 2015: Reproductive Decision-Making in a Macro-Micro Perspective. A Conceptual Framework. In: Philipov, Dimiter; Liefbroer, Aart C.; Klobas, Jane E. (Eds.): Reproductive Decision-Making in a Macro-Micro Perspective. Dordrecht: Springer: 1-15 [doi: 10.1007/978-94-017-9401-5_1].

Lindenberg, Siegwart 1985: An Assessment of the New Political Economy. Its Potential for the Social Sciences and for Sociology in Particular. In: Sociological Theory 3,1: 99114 [doi: 10.2307/202177]. 
Lück, Detlev; Diabaté, Sabine; Ruckdeschel, Kerstin 2017: Cultural Conceptions of Family as Inhibitors of Change in Family Lives. The 'Leitbild' Approach. In: Cesnuitytè, Vida; Lück, Detlev; Widmer, Eric D. (Eds.): Family Continuity and Change. Contemporary European Perspectives. Palgrave Macmillan Studies in Family and Intimate Life. London: Palgrave Macmillan: 61-86.

Lundberg, Shelly; Pollak, Robert A. 2007: The American Family and Family Economics. IZA Discussion Paper. Bonn.

Maher, JaneMaree; Dever, Maryanne 2004: What Matters to Women. Beyond Reproductive Stereotypes. In: People and Place 12,3: 11-19.

Maher, JaneMaree et al. 2004: What Women (and Men) Want. Births, Policies and Choices. Melbourne.

Mayer, Karl Ulrich 2001: Lebensverlauf. In: Schäfers, Bernhard; Zapf, Wolfgang (Eds.): Handwörterbuch zur Gesellschaft Deutschlands. Wiesbaden: VS Verlag für Sozialwissenschaften: 446-460.

Miller, Warren B. 2011: Comparing the TPB and the T-D-I-B Framework. In: Morgan, S. Philip; Sobotka, Tomáš; Testa, Maria Rita (Eds.): Reproductive Decision-Making. Vienna Yearbook of Population Research 9. Vienna: Verlag der Österreichischen Akademie der Wissenschaften: 19-29 [doi: 10.1553/populationyearbook2011s19].

Miller, Warren B.; Pasta, David J. 1994: The Psychology of Child Timing. A Measurement Instrument and a Model. In: Journal of Applied Social Psychology 24,3: 218-250 [doi: 10.1111/j.1559-1816.1994.tb00580.x].

Miller, Warren B.; Pasta, David J. 1995: Behavioral Intentions. Which Ones Predict Fertility Behavior in Married Couples? In: Journal of Applied Social Psychology 25,6: 530 555 [doi: 10.1111/j.1559-1816.1995.tb01766.x].

Miller, Warren B.; Pasta, David J. 1996: Couple Disagreement. Effects on the Formation and Implementation of Fertility Decisions. In: Personal Relationships 3,3: 307-336 [doi: 10.1111/j.1475-6811.1996.tb00119.x].

Miller, Warren B.; Pasta, David J. 2002: The Motivational Substrate of Unintended and Unwanted Pregnancy. In: Journal of Applied Biobehavioral Research 7,1: 1-29 [doi: 10.1111/j.1751-9861.2002.tb00073.x].

Miller, Warren B.; Severy, Lawrence; Pasta, David J. 2004: A Framework for Modelling Fertility Motivation in Couples. In: Population Studies 58,2: 193-205 [doi: 10.1080/0032472042000213712].

Morgan, S. Philip 1985: Individual and Couple Intentions for More Children. A Research Note. In: Demography 22,1: 125-132 [doi: 10.2307/2060991].

Morgan, S. Philip; Bachrach, Christine A. 2011: Is the Theory of Planned Behaviour an Appropriate Model for Human Fertility? In: Morgan, S. Philip; Sobotka, Tomáš; Testa, Maria Rita (Eds.): Reproductive Decision-Making. Vienna Yearbook of Population Research 9. Vienna: Verlag der Österreichischen Akademie der Wissenschaften: 11-18 [doi: 10.1553/populationyearbook2011s11].

Morgan, S. Philip; Sobotka, Tomáš; Testa, Maria Rita (Eds.) 2011: Reproductive Decision-Making. Vienna Yearbook of Population Research 9. Vienna: Verlag der Österreichischen Akademie der Wissenschaften [doi: 10.1553/populationyearbook2011].

Nauck, Bernhard 2007: Value of Children and the Framing of Fertility. Results from a Cross-Cultural Comparative Survey in 10 Societies. In: European Sociological Review 23,5: 615-629. [doi: 10.1093/esr/jcm028].

Nauck, Bernhard 2014: Value of Children and the Social Production of Welfare. In: Demographic Research 30,66: 1793-1824 [doi: 10.4054/DemRes.2014.30.66]. 
Ní Bhrolcháin, Máire; Beaujouan, Éva 2015: How Real are Reproductive Goals? Uncertainty and the Construction of Fertility Preferences. Working Paper [doi: 10.13140/ RG.2.1.3495.6884].

Passet-Wittig, Jasmin et al. 2018: Lifecourse Contexts and Instability in Perceptions of Procreative Ability among Women and Men in Germany (unpublished manuscript).

Perrier, Maud 2013: No Right Time. The Significance of Reproductive Timing for Younger and Older Mothers' Moralities. In: The Sociological Review 61,1: 69-87 [doi: 10.1111/1467-954X.12005].

Philipov, Dimiter 2011: Theories on Fertility Intentions. A Demographer's Perspective. In: Morgan, S. Philip; Sobotka, Tomáš; Testa, Maria Rita (Eds.): Reproductive Decision-Making. Vienna Yearbook of Population Research 9. Vienna: Verlag der Österreichischen Akademie der Wissenschaften: 37-45 [doi: 10.1553/populationyearbook2011s37].

Philipov, Dimiter; Klobas, Jane E.; Liefbroer, Aart C. 2015a: Reproductive DecisionMaking. A Milestone, and the Road Ahead. In: Philipov, Dimiter; Liefbroer, Aart C.; Klobas, Jane E. (Eds.): Reproductive Decision-Making in a Macro-Micro Perspective. Dordrecht: Springer: 165-178 [doi: 10.1007/978-94-017-9401-5_7].

Philipov, Dimiter; Liefbroer, Aart C.; Klobas, Jane E. (Eds.) 2015b: Reproductive Decision-Making in a Macro-Micro Perspective. Dordrecht: Springer [doi: 10.1007/978-94017-9401-5].

Pink, Sebastian 2017: Fertility and Social Interaction. A Simulation Approach. Mannheim: Universität Mannheim.

Putz, Tobias; Engelhardt, Henriette 2014: The Effects of the First Birth Timing on Women's Wages. A Longitudinal Analysis Based on the German Socio-Economic Panel. In: Journal of Family Research 26,3: 302-330 [doi: 10.3224/zff.v26i3.18990].

Rackin, Heather M.; Bachrach, Christine A. 2016: Assessing the Predictive Value of Fertility Expectations Through a Cognitive-Social Model. In: Population Research and Policy Review 35,4: 527-551 [doi: 10.1007/s11113-016-9395-z].

Rijken, Arieke; Knijn, Trudie 2009: Couples' Decisions to have a First Child. Comparing Pathways to Early and Late Parenthood. In: Demographic Research 21,26: 765-802 [doi: 10.4054/DemRes.2009.21.26].

Rosina, Alessandro; Testa, Maria Rita 2009: Couples' First Child Intentions and Disagreement. An Analysis of the Italian Case. In: European Journal of Population 25: 487502 [doi: 10.1007/s10680-009-9188-8].

Sassler, Sharon; Miller, Amanda; Favinger, Sarah M. 2009: Planned Parenthood? Fertility Intentions and Experiences Among Cohabiting Couples. In: Journal of Family Issues 30,2: 206-232 [doi: 10.1177/0192513X08324114].

Schippers, Joop 2011: The Economic Rationality of Late Parenthood. In: Beets, Gijs; Schippers, Joop; te Velde, Egbert R. (Eds.): The Future of Motherhood in Western Societies. Late Fertility and its Consequences. Dordrecht/New York: Springer: 91-105 [doi: 10.1007/978-90-481-8969-4_7].

Schneider, Norbert F.; Diabaté, Sabine; Ruckdeschel, Kerstin (Eds.) 2015: Familienleitbilder in Deutschland. Kulturelle Vorstellungen zu Partnerschaft, Elternschaft und Familienleben. Beiträge zur Bevölkerungswissenschaft 48. Opladen: Budrich.

Schneider, Thorsten 2016: Geburten aus geplanten und ungeplanten Schwangerschaften. Die Relevanz von Bildung, Arbeitslosigkeit und Partnerschaft. In: Kölner Zeitschrift für Soziologie und Sozialpsychologie 68,1: 1-28 [doi: 10.1007/s11577-015-0353-2]. 
Shirani, Fiona 2013: The Spectre of the Wheezy Dad. Masculinity, Fatherhood and Ageing. In: Sociology 47,6: 1104-1119 [doi: 10.1177/0038038512469063].

Shreffler, Karina M. et al. 2018: Partner Congruence on Fertility Intentions and Values: Implications for Birth Outcomes. In: Journal of Social and Personal Relationships [doi: 10.1177/0265407518787232].

Spéder, Zsolt; Kapitány, Balázs 2015: Influences on the Link between Fertility Intentions and Behavioural Outcomes. Lessons from a European Comparative Study. In: Philipov, Dimiter; Liefbroer, Aart C.; Klobas, Jane E. (Eds.): Reproductive Decision-Making in a Macro-Micro Perspective. Dordrecht: Springer: 79-112 [doi: 10.1007/978-94-0179401-5_4].

Stein, Petra; Willen, Sebastian; Pavetic, Monika 2014: Couples' Fertility Decision-Making. In: Demographic Research 30,63: 1697-1732 [doi: 10.4054/DemRes.2014.30.63].

Testa, Maria Rita 2012: Couple Disagreement about Short-Term Fertility Desires in Austria. Effects on Intentions and Contraceptive Behavior. In: Demographic Research 26,3: 63-98 [doi: 10.4054/DemRes.2012.26.3].

Testa, Maria Rita; Cavalli, Laura; Rosina, Alessandro 2011: Couples' Childbearing Behaviour in Italy. Which of the Partners is Leading it? In: Morgan, S. Philip; Sobotka, Tomáš; Testa, Maria Rita (Eds.): Reproductive Decision-Making. Vienna Yearbook of Population Research 9. Vienna: Verlag der Österreichischen Akademie der Wissenschaften: 157-178 [doi: 10.1553/populationyearbook2011s157].

Testa, Maria Rita; Cavalli, Laura; Rosina, Alessandro 2014: The Effect of Couple Disagreement about Child-Timing Intentions. A Parity-Specific Approach. In: Population and Development Review 40,1: 31-53 [doi: 10.1111/j.1728-4457.2014.00649.x].

Thomson, Elizabeth; Hoem, Jan 1998: Couple Childbearing Plans and Births in Sweden. In: Demography 35,3: 315-322 [doi: 10.2307/3004039].

Vikat, Andres et al. 2007: Generations and Gender Survey (GGS). Towards a Better Understanding of Relationships and Processes in the Life Course. In: Demographic Research 17,14: 389-440 [doi: 10.4054/DemRes.2007.17.14].

Dr. Uta Brehm $(\varangle)$, Prof. Dr. Norbert F. Schneider. Federal Institute for Population Research. Wiesbaden, Germany.

E-mail: uta.brehm@bib.bund.de,post@bib.bund.de

URL: https://www.bib.bund.de/DE/Institut/Mitarbeiter/Brehm/Brehm.html https://www.bib.bund.de/DE/Institut/Mitarbeiter/Schneider/Schneider.html 


\section{Comparative Population Studies}

WWW.comparativepopulationstudies.de

ISSN: 1869-8980 (Print) - 1869-8999 (Internet)

\section{Published by}

Prof. Dr. Norbert F. Schneider

Federal Institute for Population Research D-65180 Wiesbaden / Germany

\section{(c) BY-SA}

2019

\section{Managing Editor \\ Prof. Philip Rees \\ Dr. Katrin Schiefer}

\section{Copy Editor}

Julia Luther

\section{Editorial Assistant}

Beatriz Feiler-Fuchs

Wiebke Hamann

\section{Layout \\ Beatriz Feiler-Fuchs \\ E-mail:cpos@bib.bund.de}

\section{Scientific Advisory Board}

Karsten Hank (Cologne)

Michaela Kreyenfeld (Berlin)

Marc Luy (Vienna)

Natalie Nitsche (Vienna)

Peter Preisendörfer (Mainz)

Zsolt Spéder (Budapest)

Rainer Wehrhahn (Kiel)

\section{Board of Reviewers}

Martin Abraham (Erlangen)

Laura Bernardi (Lausanne)

Hansjörg Bucher (Bonn)

Claudia Diehl (Konstanz)

Andreas Diekmann (Zurich)

Gabriele Doblhammer-Reiter (Rostock)

Jürgen Dorbritz (Wiesbaden)

Anette Eva Fasang (Berlin)

E.-Jürgen Flöthmann (Bielefeld)

Alexia Fürnkranz-Prskawetz (Vienna)

Beat Fux (Salzburg)

Joshua Goldstein (Berkeley)

Sonja Haug (Regensburg)

Hill Kulu (Liverpool)

Aart C. Liefbroer (The Hague)

Kurt Lüscher (Konstanz)

Emma Lundholm (Umeå)

Nadja Milewski (Rostock)

Dimiter Philipov (Vienna)

Roland Rau (Rostock)

Tomáš Sobotka (Vienna)

Jeroen Spijker (Barcelona)

Olivier Thévenon (Paris)

Helga de Valk (Brussels)

Heike Trappe (Rostock)

Michael Wagner (Cologne) 